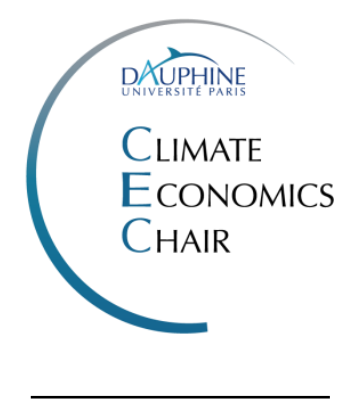

\section{KEYWORDS}

Renewable energy

Technology diffusion

Demand pull instruments

\section{WORKING PAPER} $n^{\circ} 2017-05 \cdot$ Mai 2017

\section{DEMAND PULL INSTRUMENTS AND THE DEVELOPMENT OF WIND POWER IN EUROPE:

\author{
A counter-factual analysis
}

Marc BAUDRY1,2, Clément BONNET1,2

Renewable energy technologies are called to play a crucial role in the reduction of greenhouse gas (GHG) emissions. Since most of these technologies did not yet reach grid parity, public policies can rely on two types of approach to stimulate innovation: supply-push and demand-pull. The latter aims at creating demand for new technologies and at stimulating their diffusion. Nevertheless, due to the complex self-sustained dynamics of diffusion and to spillovers between the countries it is hard to determine whether newly installed capacities are imputable to national support policies and/or to policies implemented by neighbor countries. The paper addresses this problem. A micro-founded model of technology diffusion is developed and calibrated. It captures the influence of demand-pull policies on wind power installed capacities for six European countries over the last decade. A counter-factual analysis is carried out to assess the impact of demand-pull policies on wind power development by taking into account the interplay between national policies via spillovers. 


\title{
Demand-pull instruments and the development of wind power in Europe: a counter-factual analysis
}

\author{
Marc Baudry \\ Climate Economics Chair \\ EconomiX (UMR CNRS 7235), University of Paris Ouest Nanterre la Défense \\ Clément Bonnet \\ Climate Economics Chair \\ EconomiX (UMR CNRS 7235), University of Paris Ouest Nanterre la Défense
}

May 11, 2017

\begin{abstract}
Renewable energy technologies are called to play a crucial role in the reduction of greenhouse gas (GHG) emissions. Since most of these technologies did not yet reach grid parity, public policies can rely on two types of approach to stimulate innovation: supply-push and demand-pull. The latter aims at creating demand for new technologies and at stimulating their diffusion. Nevertheless, due to the complex self-sustained dynamics of diffusion and to spillovers between the countries it is hard to determine whether newly installed capacities are imputable to national support policies and/or to policies implemented by neighbor countries. The paper addresses this problem. A micro-founded model of technology diffusion is developed and calibrated. It captures the influence of demand-pull policies on wind power installed capacities for six European countries over the last decade. A counter-factual analysis is carried out to assess the impact of demand-pull policies on wind power development by taking into account the interplay between national policies via spillovers.
\end{abstract}

\section{Introduction}

In November 2014, the European Union has reaffirmed its ambition to produce $27 \%$ of its electricity from renewable sources by 2030. As most renewable energy technologies are not yet cost-competitive, increasing their share in the energy mix needs support from public authorities. In the late 2000s the bulk of European countries had implemented public policies dedicated to the promotion of renewable energies [30]. Among these policies, there is a clear predominance of the demand-pull approach over the supply-push alternative [34]. The former aims at stimulating the deployment of new renewable energy generation capacities whereas the latter targets the development of innovative solutions. A demand-pull support policy, despite the several forms it can takes, follows the same principle: granting 
to renewable energy producers a higher tariff than the electricity market price. Albeit the sign of the causal link between the tariff and the installed capacities of renewable energy is quite intuitive, i.e. positive, little is known about the magnitude of this link. Demand-pull instruments have been initially implemented by governments without a precise idea of their results in terms of installed capacities ${ }^{1}$. Indeed, demand-pull instruments allow public authorities to control the revenue that renewable energy producers will earn by setting the payment they will receive for renewable electricity. As investment decisions are made based on the profitability, the investment cost of the power plant will also determine the investment decision. The uncertainty faced by governments about the link between the support instrument and the installed capacities comes from the difficulty to forecast the evolution of this cost, as it depends from several factors among which: (i) the national experience, (ii) the foreign experience.

This paper aims at quantifying the causal link between demand-pull instruments and installed capacities by assessing the amount of installed capacities of onshore wind power that are imputable to demand-pull support instruments. This is done by distinguishing between the installed capacities of wind power that are imputable to the national support scheme on one hand, and those that are imputable to the demand-pull instruments implemented in other European countries. Now that electricity generated with onshore wind power is close to grid parity after years of public support, this technology constitutes a good case study to investigate the causal link described above. A counterfactual analysis of the impact of demand-pull instruments on the deployment of wind power installed capacities in six European countries is conducted (Germany, Denmark, Italy, Spain, Portugal and France $\left.^{2}\right)$. By contrast with the burgeoning literature that analyzes the drivers of the development of renewable energy generation capacities with ad hoc econometric models ([25]; [26] and [19]), such a counter-factual analysis relies on a structural model of the commissioning of new wind power units. Moreover, counter-factual analysis is a key concept for the ex post analysis of public policies, either to characterize what the situation would have been in the absence of the policy or, conversely, to identify what the situation could have been if a given policy had been implemented. Our counter-factual analysis proceeds in three steps.

First, a micro-founded diffusion model of a new technology is developed. The model builds on the work of Kemp [20] who proposed to reproduce the diffusion pathway of a new technology by representing the investment decision at the individual level. His approach sharply contrasts with the usual holistic approach that dates back to the seminal works on technology diffusion of Griliches [15] and Mansfield [24]. In the present paper, the investment is more specifically triggered by the expected return-oninvestment (RoI) of a MW of wind power capacity which is referred to as the benchmark value of the RoI. Differences in climatic conditions or sites accessibility, among others, generate heterogeneity across the levels of RoI reached by actual sites. A distribution of actual values of the RoI around

\footnotetext{
${ }^{1}$ The German case is illustrative of this difficulty to manage the volume of installed capacities by adjusting the level of demand-pull support. In order to limit the growth of solar PV, and the cost of the scheme, the support has been reformed in 2009. The idea is to adjust the tariff paid to new PV generators with respect to the installed capacities of the previous year. Despite this ingenious system, the newly installed capacities in 2010 will be equal to 3806 MW, urging the German parliament to undertake an exceptional revision of the support policy.

${ }^{2}$ Despite its relatively high amounts of installed capacities of wind power, United-Kingdom is not included in the analysis as this country has chosen a system of certificates to support renewable energy diffusion. The system has suffered from a leakage of subsidies as a high share of the value of the certificates was captured by electricity suppliers [39].
} 
the benchmark value (the expected RoI) is thus introduced to capture this heterogeneity. The microfounded version of the diffusion model proposed in the paper exhibits several interesting and realistic properties: (1) the need for a public support to impulse the technology diffusion in the case none of the sites to commission a MW of wind power is profitable; (2) the possibility for the diffusion process to be stopped before the full deployment is reached; (3) the role of the variations of the RoI from year to year and (4) the contribution of the cumulative deployment at time $t$ on the decisions taken in $t+1$.

Second, we describe how the expected RoI is computed from a period to another. Two types of factors impact the level of expected RoI: exogenous factors and endogenous factors. Exogenous factors are, for instance, the price paid to the producer per generated $\mathrm{kWh}$. It represents the demand-pull support policies in the scenario that reproduces the observed diffusion of wind power and it takes a lower value when simulating the counter-factual scenarios. Endogenous factors are all the factors that intervene in the expected RoI and that depend on the level of deployment. More specifically, a learning curve approach is adopted to capture the evolution of investment costs. The learning dynamics also encompass the role of scaling that has significantly contributed to the increase in turbines prices [7].

Third, we use yearly data, at the country level, on installed wind power to calibrate the diffusion model. The counter-factual analysis then builds on the calibrated causal relation between the dynamics of the benchmark RoI and the newly built units of generation (in MW). More precisely, the payment received by producers under a demand-pull scheme are replaced by the counter-factual values of payment that would have prevailed in the absence of a given policy instrument in order to generate the counter-factual deployment of wind power. Beyond the analysis of the effect of the national policy of each country as if it was isolated, the paper stresses the importance of the interplay between these support policies that benefit from reciprocal spillovers. Indeed, even if some European countries have play a leading role in the development of wind power (e.g. Denmark, Germany and Spain) whereas others may be considered as laggards (e.g. France, Italy and Portugal), the relevant market for wind turbines is rather European than domestic-wide. A major consequence is that support policies in neighbor countries may have substantially contributed to learning for the benefit of each country. The research strategy followed by the paper is introduced in section 2 . The model is developed in section 3. Subsection 3.1 details the micro-founded diffusion model which properties are then discussed in subsection 3.2. The profitability index used as the driver of development decisions and its link with the demand pull instruments are presented in section 4. After a short review of the use of a Return-on-Investment index in subsection 4.1, its modeling is developed in subsection 4.2. The focus of subsection 4.3 is on the sources of heterogeneity among countries, both exogenous and endogenous. Section 5 presents the calibration of the model (in subsection 5.1) and the results of the counter-factual analysis (in subsection 5.2). Section 6 concludes by examining the policy implications.

\section{Research strategy}

The empirical analysis of the diffusion of a new technology finds its origins in the pioneering work of Griliches [15] and Mansfield [24]. Originally, it was intended to formally reproduce the S-shaped time path of the rate of diffusion typically observed for many technologies. This analysis is usually 
said to be holistic as it provides an aggregated representation of individual decisions which are not explicitly analyzed but are assumed to interact through the transmission of information and feedback 3 . If the role of economic and financial incentives was initially disregarded, some authors have sought to remedy to this weakness (see e.g. [11]; [1] and [2] ; [16]). Usha Rao and Kishore [33] propose a survey of applications of this approach to the case of renewable energy technologies. The approach, however, remains devoid of an explicit representation of a process of rational economic decision.

The micro-founded approach to the diffusion of onshore wind power proposed in this article is inspired by the work of Kemp [20], although it was on a different technology. Unlike the holistic approach, the proposed model details the decision to install a MW of wind power. The investment is assumed to be realized if it is profitable as measured by the average return-of-investment per generated $\mathrm{kWh}$ over the turbine lifetime. However, under similar economic conditions, the profitability levels of new investments in wind power capacities are heterogeneous in a country. This heterogeneity results from differences in terms of climatic conditions, site access, local acceptability, design of the wind farm and, of course, from an element of chance. This is captured by a distribution of the profitability at the individual level around an average value. The average level of profitability, a position parameter of the distribution, will vary among years due to learning-by-doing effects, turbines scaling and some exogenous factors including demand-pull policies.

The micro-founded model of diffusion aims at explaining the time path of diffusion of wind power by the variations of the average profitability over time. Hence, the theoretical profitability of a MW of wind power is computed and its variations over time will determine the path of diffusion of the technology.

In this study two geographical stages of learning influence the investment cost of wind power. First, for a given country the European learning from the experience accumulated by the other countries will lower the domestic investment cost. In this extent, it measures the learning-by-doing spillovers from the rest of Europe to the country. Second, each country experiences a national learning from the capacities installed within its borders. Hence, the assumption is made that for a given country the conversion of accumulated experience into cost reduction is not the same whether it is gathered at the national or regional (i.e. European) levels. Both types of learning react to the cumulative installed capacities of wind power which is considered as a good proxy of the accumulated experience [22]. Contrary to the holistic approach, economic incentives, learning and diffusion are thus tightly linked in the micro-founded model.

The main steps of the method implemented to assess the impact of demand-pull policies are represented on Figure 1. It is divided in two steps. First, the parameters of the micro-founded diffusion model are calibrated in order to replicate, as good as possible, the observed time paths of diffusion of wind power technology in the six analyzed countries; namely Denmark, Germany, Spain, Italy, Portugal and France. More details about these parameters and the way they are calibrated are given in subsection 5.1. Both the inputs and the outputs of the model are known. The inputs are the payments received by producers, i.e. demand-pull policies and/or electricity price, and some contextual variables that influenced wind power profitability. The outputs of the model are the newly installed capacities.

\footnotetext{
${ }^{3}$ The term 'epidemiological' is sometimes used in place of the term 'holistic' in reference to the dissemination of infectious diseases that also follows an S-shaped curve.
} 


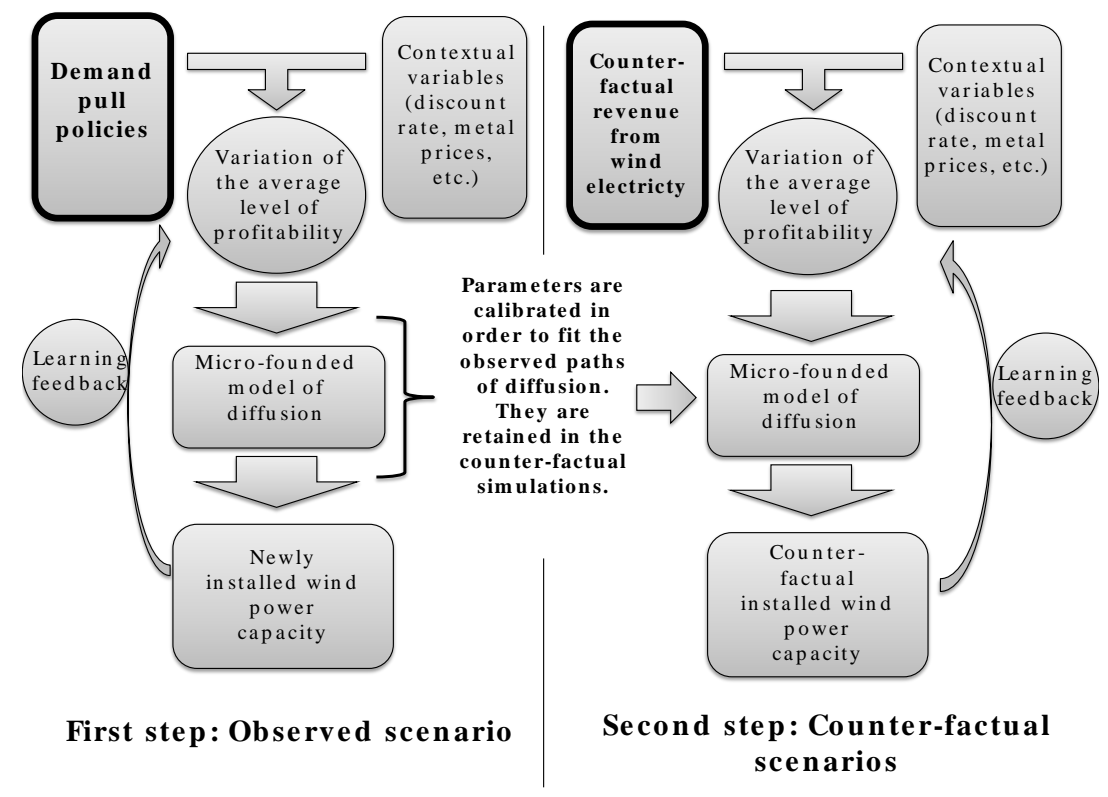

Figure 1: Schematic diagram of the research strategy.

The link from a time period $t$ to the next is made via the impact of the cumulative capacities on the variation of the average profitability level.

In the second step of the research strategy, the same parameters values are retained for simulating counter-factual scenarios. Contextual variables do not change but the revenue from electricity does as producers do not benefit anymore from demand-pull policies. Hence, the cumulative installed wind power capacity is endogenously determined with respect to profitability and consequently influences: (1) the learning that benefits to new cohorts of wind power installations, (2) the average rated power of newly installed turbines that drives its cost and its productivity. The investigated scenarios are presented in Table 1.

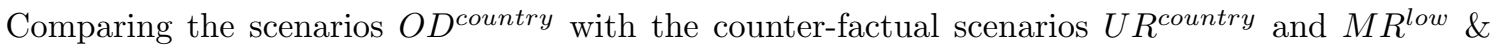
$M R^{\text {high }}$ allows to estimate the share of wind power capacities that is imputable to demand-pull policies. For the purpose of counter-factual analysis, two types of scenarios are investigated and described in Table 1: Unilateral Removal $\left(U R^{\text {country}}\right)$ and Multilateral Removal $\left(M R^{\text {low }} \& M R^{\text {high }}\right)$. Thereafter, we elaborate on how the electricity price is chosen in each type of scenario. In an alternative reality without demand-pull support, it can be assumed that producers would have received the market price. It is well known that the growing share of variable energies fed into the grid contributes to lower the spot prices of electricity ([31]; [21]; [17]; [14]; [9]; [8] and [4]). In this extent, when simulating counter-factual scenarios an ideal model would adjust electricity prices in accordance with the cumulative electricity generation. However, this effect is not considered when simulating $U R^{\text {country }}$ scenarios as the decision to invest in wind power relies on investors expectations. A reasonable assumption is that investors expect the European electricity markets to be more and more integrated as supported by the European directive 96/92 and the European directive 2003/54 on the European electricity markets. Hence, it is 


\begin{tabular}{|c|c|}
\hline Observed Diffusion $\left(O D^{\text {country }}\right)$ & $\begin{array}{l}\text { Parameters are calibrated in order to fit as good as } \\
\text { possible the observed national time paths of diffusion. } \\
\text { Their values are different for each country. } \\
\text { Hence we have six different } O D^{\text {country }} \text { scenarios. }\end{array}$ \\
\hline 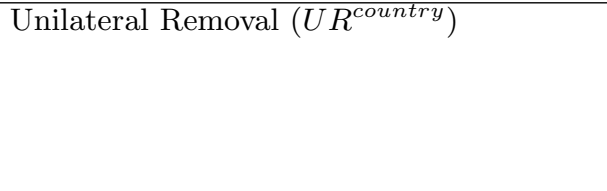 & $\begin{array}{l}\text { Six scenarios are simulated, in which a country } \\
\text { unilaterally suppresses its demand-pull support } \\
\text { scheme(s). The direct impact on the domestic installed } \\
\text { capacities and the indirect impact on the other countries are } \\
\text { assessed }\end{array}$ \\
\hline Multilateral Removal $\left(M R^{\text {low }} \& M R^{\text {high }}\right)$ & $\begin{array}{l}M R^{l o w}: \text { the six countries do not implement their } \\
\text { demand-pull policies so that wind electricity } \\
\text { producers only receive the electricity market price. } \\
\text { The electricity price is assumed to be equal to the } \\
\text { observed market price over the analyzed period. } \\
\text { The overall effect on the six countries is assessed. }\end{array}$ \\
\hline & $\begin{array}{l}M R^{\text {high }}: \text { Contrary to scenario } M R^{\text {low }} \text {, the } \\
\text { electricity market prices are increased in order to } \\
\text { capture the merit order effect. }\end{array}$ \\
\hline
\end{tabular}

Table 1: Presentation of the replicated and simulated scenarios.

assumed that, taken in isolation, the support policy of a country sees its impact on electricity prices being diluted in the European electricity markets. In other words, it is assumed that the demand-pull policy of an isolated country does not significantly impact the electricity market ${ }^{4}$. Nonetheless, this assumption is ruled out when considering that all national policies are jointly removed as done in the two scenarios $M R^{\text {low }} \& M R^{\text {high }}$. To address this issue two variations are considered. First, the observed prices over the analyzed period are retained in order to estimate the lower bound of what would have been the diffusion of wind power in the absence of demand-pull policies, this scenario is denoted $M R^{\text {low }}$. It is a lower bound as in reality it is likely that the prices would have been higher with a lower share of wind electricity fed into the grid. Consequently, investments in new capacities would have been higher. To tackle this issue the second variation, denoted $M R^{h i g h}$, follows the same approach with slightly increased electricity prices to estimate the upper bound of the counter-factual diffusion of wind power when demand-pull polices are jointly removed. We follow Ketterer [21] by considering that the electricity spot price has been $1.46 \%$ lower for every additional percent of wind power in the total electricity load of a country ${ }^{5}$. Although the study of Ketterer only focuses on Germany, we use this value as a rule of thumbs for the six countries. More precisely, in the scenario $M R^{h i g h}$ it is implicitly considered that wind integration does not impact electricity prices while in reality even a lower diffusion of wind power would have induce a decrease of the average electricity prices. In this extent, these two scenarios allow us to construct an interval in which the 'true' diffusion of wind power in the absence of demand-pull support would have lie.

Finally, it must be underlined that the counter-factual analysis investigates the case for a removal of financial support but cannot dispose from the assumption of priority access to the grid. Moreover, it

\footnotetext{
${ }^{4}$ This assumption is more fragile in the case of Germany as this country fed large amounts of wind electricity into the grid.

${ }^{5}$ Time series of counter-factual electricity prices are built by increasing by $1.46 \%$ the observed price for every percent of wind power in the electricity load.
} 
is difficult to apprehend the time profile of the electricity generation from wind power that determines producers' revenue. Most of the time, windy hours correspond to off-peak hours, preventing wind producers from recovering their fixed costs [3]. In this analysis only yearly average prices are retained for computing profitability.

\section{The Model}

\subsection{Model Setting}

The model deals with the decision to build a unit of installed capacity of wind power; the retained unit of diffusion of the wind technology is a MW of installed capacity. The investment is realized if and only if its profitability is positive. Since the level of profitability is heterogeneous across projects due, for instance, to climatic peculiarities we consider that the level of profitability $R$ for a given cohort $t$ follows a two parameters distribution with a partial density function $f\left(R ; \mu_{t}, \sigma\right)$ where $\mu_{t}$ is the average Return-on-Investment and $\sigma$ is the standard deviation. It allows us to capture the heterogeneity of the investment projects without having to collect detailed information project by project. It should be noted that the two parameters do change from a country to another. Moreover, the average level of profitability $\mu_{t}$ will vary in time due to modifications of demand-pull policies, variations of the investment costs and some other exogenous factors. The sources of variations of $\mu_{t}$ are detailed in subsection 4.2. The standard deviation $\sigma$ is assumed to be independent from demand-pull policies so that its value is time invariant, whereas the mean $\mu_{t}$ changes among scenarios. The model intends to explain the diffusion of wind power by the variations of $\mu_{t}$. An illustration of the effect of such a variation for a given year $t$ is given by Figure 2. It illustrates the case of an increase of the average profitability, so that the distribution of the profitability level shifts to the right.

The general idea of the model is as follows. At the beginning of a given year $t$, all the MWs that are profitable $(R>0)$ are developed, or have been previously developed. It is expressed as a fraction $1-F\left(0 ; \mu_{t}, \sigma\right)$ of the total potential, denoted $k_{\max }$ that represents a theoretical upper bound for the diffusion of wind power. Assuming an increase of the average profitability between $t$ and $t+1$, so that $\Delta \mu_{t}>0$, the newly installed capacities are the difference between the total amount of profitable projects and the projects that were already profitable and consequently already developed. Hence, the capacities that are installed during the year $t$ are $F\left(0 ; \mu_{t}, \sigma\right)-F\left(0 ; \mu_{t+1}, \sigma\right)$. In the case the average profitability decreases from year $t$ to the next year it is assumed that no new capacities are installed.

Expressed as a fraction of $k_{\max }$, the wind power capacities developed during year $t$ may formally be written as

$$
\frac{\Delta k_{t+1}}{k_{\max }}=\left\{\begin{array}{ccc}
F\left(0 ; \mu_{t}, \sigma\right)-F\left(0 ; \mu_{t+1}, \sigma\right) & \text { if } & \Delta \mu_{t}>0 \\
0 & \text { if } & \Delta \mu_{t} \leq 0
\end{array}\right.
$$

In practice, the model is implemented in a slightly different way. Indeed, our purpose is to replicate the observed diffusion, as best as possible, by calibrating the parameters of the model in order to realize a counter-factual analysis. 


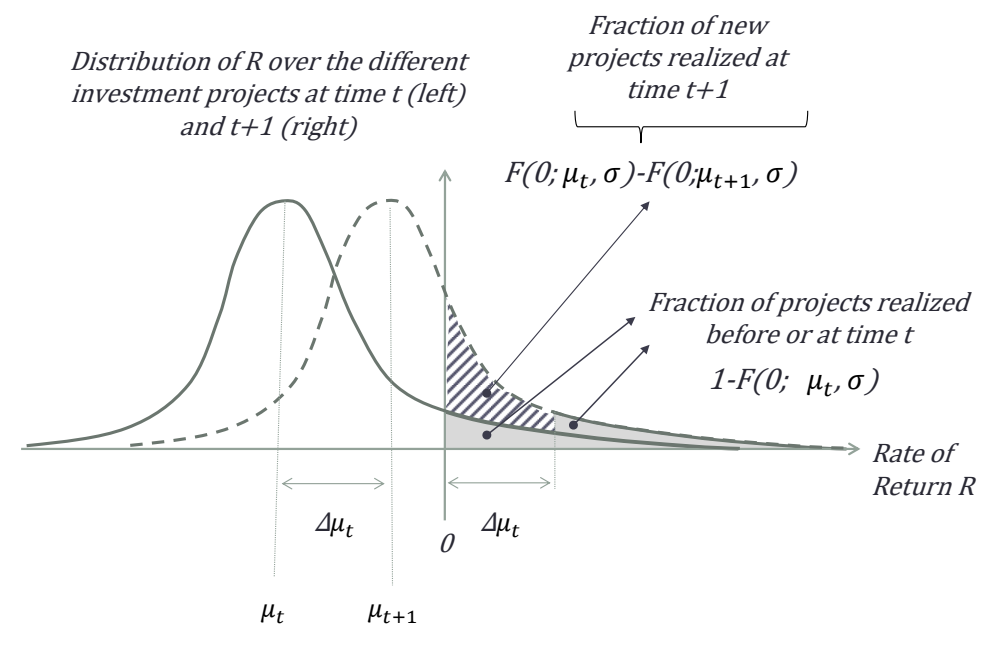

Figure 2: Micro-foundations of diffusion dynamics: impact of an increase of the average level of profitability on the newly developed capacities.

The counter-factual analysis relies on an openloop approach to the dynamics of diffusion. In order to be consistent with the data observed at the beginning of the replicated period, two initial conditions have to be satisfied. These two conditions are written

$$
\frac{F\left(R_{\max } ; \mu_{0}, \sigma\right)-F\left(0 ; \mu_{0}, \sigma\right)}{F\left(R_{\max } ; \mu_{0}, \sigma\right)}=\frac{k_{0}}{k_{\max }}
$$

and

$$
\frac{F\left(0 ; \mu_{0}, \sigma\right)-F\left(0 ; \mu_{1}, \sigma\right)}{F\left(R_{\max } ; \mu_{0}, \sigma\right)}=\frac{\Delta k_{0}}{k_{\max }} .
$$

Condition (2) states that the share of the wind power capacity that is installed at the beginning $(t=0)$ of the replicated period amounts to $k_{0} / k_{\max }$. Satisfying this condition generally requires to truncate the distribution of profitability. Indeed, considering the case for a symmetric distribution of $R$ and a positive value $\mu_{0}$ of the initial average profitability, which is also the median profitability. Then, more than half of the potential $k_{\max }$ would have been already developed at $t=0$, which is obviously too restrictive. Therefore, we assume that $F$ is truncated to the right by $R_{\max }$ so that the profitability does not exceed this level. However, the truncation introduces another unknown parameter $R_{\max }$. We thus introduce the additional condition (3) which states that the share of capacities added during the first period of diffusion amounts to $\Delta k_{0} / k_{\max }$. Conditions (2) and (3) can be rewritten as

$$
\kappa=\frac{k_{0}}{F\left(R_{\max } ; \mu_{0}, \sigma\right)-F\left(0 ; \mu_{0}, \sigma\right)}
$$


and

$$
\kappa=\frac{\Delta k_{0}}{F\left(0 ; \mu_{0}, \sigma\right)-F\left(0 ; \mu_{1}, \sigma\right)}
$$

where $\kappa=k_{\max } /\left(F\left(R_{\max } ; \mu_{0}, \sigma\right)\right)$. For known parameters of $F$, the value of $\kappa$ is deduced from condition (5) and is sufficient to generate the dynamics of capacities. Indeed, adapting (1) to the truncated distribution yields

$$
\Delta k_{t}=\left\{\begin{array}{ccc}
\kappa\left(F\left(0 ; \mu_{t}, \sigma\right)-F\left(0 ; \mu_{t+1}, \sigma\right)\right) & \text { if } & \Delta \mu_{t}>0 \\
0 & \text { if } & \Delta \mu_{t} \leq 0
\end{array}\right.
$$

The value of $R_{\max }$ is not required on (6) but it can be extracted from condition (4). In the next subsection the properties of the model are emphasized. Then, section 4 details how the variations of the average profitability are computed.

\subsection{Properties of the diffusion process}

A first interesting feature of the dynamics of diffusion is that, if the profitability is initially negative for all capacity units the diffusion process cannot start. This more specifically occurs if $R_{\max }$ is negative.

Two factors may trigger diffusion. First, national public policies and their positive effects on the revenue may allow the diffusion to start. Second, an increase of the European cumulative installed capacities, via learning-by-doing, may lower investment cost. This latter effect underlines the role of knowledge spillovers on the diffusion of a new technology. More precisely, it takes into account how foreign support policies may contribute to the national deployment of wind power.

Another interesting feature is that the diffusion can stop, at least temporarily, before the upper bound of wind power capacity is reached, i.e. before $k_{t}=k_{\max }$. This arises when the expected profitability decreases substantially from a period to the next. It can result, for instance, from a deterioration of economic conditions, from an increase of the prices of metals used to construct wind turbines or from lower public supports. It may follow on from the shape of the distribution of $R$. Indeed, when many capacities have already been developed, the remaining potential MWs have their profitability level $R$ on the left tail of the distribution represented in Figure 2. Given that the distribution is single peaked, the further they are on the left, the thicker is the tail and, consequently, the smaller is the proportion of new developed capacities for a given translation $\Delta \mu_{t}$ of the distribution to the right. It follows that the diffusion process is more likely to be stopped due to a decrease of average profitability when many capacity units have already been developed. This sharply contrasts with the holistic approach that is not able to explain why the diffusion process can stop before being completed. In the same idea, the diffusion could be restarted by exogenous shocks that positively affect the profitability. Such shocks are for instance a decrease of metals prices, a more profitable support provided by demand-pull policies or an increase of wind capacities installed abroad that benefits to national investors due to spillovers.

A last feature that substantially distinguishes the micro-founded model of diffusion from holistic models is that the dynamics of the proportion of developed capacities is led by the variations of the average profitability from year to year. Note that it does not mean that the policy support necessarily 
needs to increase over time to induce a diffusion of wind power as the learning effect positively affects the average profitability.

\section{Variations of the profitability index $\left(\Delta \mu_{t}\right)$}

\subsection{Renewable energy diffusion and the link with the profitability: a short literature review}

For the purpose of modeling, using a single criteria to trigger investment in new generation capacities is a meaningful alternative to the traditional optimization led decision process. Mercure et al. [27] develop a model of the electricity sector, driven by innovation, where investors make their decisions relative to the Levelized Cost of Energy ( $\mathrm{LCoE}$ ) of the different generation technologies included in the model. In order to gain realism, the authors apply a probabilistic distribution to these LCoEs, representative of the geographical heterogeneity. However, using the $\mathrm{LCoE}$ as the driver of investment decisions neglects the role of demand-pull support scheme. In this vein, several studies have been realized using measures of the expected profitability of renewable power plants. Here, the focus is on the studies linking profitability and policy instruments supporting renewable energy. Mir-Artigues and del Río [28] highlight the possibility to encompass several economic instruments by using the returnon-investment. They review all the combinations of three types of instruments (revenue improving instruments, investment subsidies and low rate loans) that lead to the same level of profitability. Profitability metrics also make it possible to assess the changes in the design of an instrument, as it is done in [12] and [18]. While the former does not build the bridge between the return-on-investment of renewable energy power plants and the deployment of additional capacities, the latter does. In [18] the Net Present Value (NPV) of total generation of a power plant is included in an econometric analysis. In our view, it is a first step to improve our understanding of the determinants of the investment in renewable energy power plants. Jenner et al. [19] estimate a fixed effects model based on the computation of the return-on-investment of two technologies: solar photovoltaic and onshore wind. By doing so, they estimate the effects of the revenue improving instruments in 26 countries. Their study concludes that demand-pull policies have contributed to wind and solar power deployment. However, they do not consider the impact of newly built capacities on the evolution of the cost of renewable energies. Actually, the yearly LCoEs they use to compute the profitability are taken from learning curves that assume a steady cost decrease that contrasts with the observed data [46], especially with regard to the increase in turbines prices observed during the mid-late 2000s. Consequently, this assumption is ruled out in the present article as the factors explaining the rise of turbines cost are included in the model, as explained below.

\subsection{Modeling the variations of the average profitability}

In the model presented in subsection 3 a key role is given to the average level of profitability $\mu$. The value of this parameter at $t=0$ is calibrated and what is of interest for us is how its variations affect the diffusion of wind power technology. In order to represent these variations a theoretical level 
of profitability, denoted $R o I_{c, t}^{\omega}$, is modeled in order to integrate the effects of demand-pull policies, among other effects, on the profitability of wind power. Hence, the variations of $\mu_{t}$ are defined by

$$
\Delta \mu_{t}=\Delta \operatorname{RoI}_{c, t}^{\omega} .
$$

The average return-on-investment per kWh of generated electricity over a turbine's lifetime for a wind plant installed at time $t$ in country $c$ in a scenario $\omega$ is computed as

$$
\operatorname{RoI} I_{c, t}^{\omega}=\frac{\operatorname{Revenue}\left(k_{t-1}^{\omega}\right)-\operatorname{Cost}\left(k_{t-1}^{\omega}\right)}{\operatorname{Cost}\left(k_{t-1}^{\omega}\right)}
$$

Cohort $t$ represents all wind capacities that have been commissioned at year $t$ and that are affected by the same economic conditions. Revenue(.) and $\operatorname{Cost}($.$) are expressed as functions of the European$ cumulative capacity $k_{t-1}^{\omega}$ at time period $t-1$ in a scenario $\omega$. The specifications of these functions are presented hereinafter and a detailed discussion about how they are constructed is given in Appendix B.

The analysis seeks to investigate the role of demand-pull policies in wind technology diffusion. Obviously, these policies have not only impacted revenue from wind electricity generation. Actually, demand-pull policies have been implemented with the main objective to stimulate wind power diffusion in order to reduce wind electricity cost through learning-by-doing. Hence, the investment cost for a given year $t$ depends on the cumulative installed capacity at year $t-1$. Learning-by-doing is thus incorporated in $\operatorname{Cost}($.$) in order to take into account the impact of wind power diffusion on investment$ cost.

At first sight, it can be done by using the simple form of learning curve $C_{t}=C_{r e f}\left(M W_{t-1} / M W_{r e f}\right)^{-\beta}$, where the cost $C_{t}$ at time $t$ depends on the cumulative installed capacity $M W_{t-1}$ relative to $M W_{\text {ref }}$ the installed capacity at the year of reference ${ }^{6}$, on an initial cost value $C_{r e f}$ and on a learning-by-doing elasticity $\beta$. Hence the learning rate is computed as $1-2^{-\beta}$. Nonetheless, an increase in investment cost has been observed in all the countries considered in this analysis during the mid-late 2000s. Consequently, the analysis would be biased if using a simple learning curve in the counter-factual analysis as the investment cost would mechanically decrease while in reality it has increase. To solve this problem, the main factors responsible for the increase of investment costs have to be incorporated in the learning curve. According to Bolinger and Wiser [7], $58 \%$ of the increase in the prices of turbines in the US between 2002 and 2008 are imputable to turbines scaling and to higher metals prices ${ }^{7}$. Their diagnostic applies to Europe as the majority of the turbines imported in the US between 2002 and 2010 were European (in average, 61\% of yearly turbines imports between 2002 and 2010 are from UK, Denmark and the Euro zone; [7]). The two factors are included in the specification of the turbine cost. Other factors responsible for the increase of turbines cost such as labor costs, warranty provisions or profit margins are not considered here as they require hard-to-access data; energy prices are neglected because they only had a small effect. To incorporate the effects of turbines scaling and metal prices the investment cost is decomposed as

\footnotetext{
${ }^{6}$ The chosen year of reference does not impact the result, see [13].

${ }^{7}$ When computing these shares, the effects of currency movements are excluded as they just represent the loss of value of the Dollar relative to the Euro.
} 


$$
I C_{c, t}^{\omega}=\left(T C_{c, t}^{\omega}+B O S_{c}^{r e f}\right)\left(\frac{k_{\text {national }, t-1}^{\omega}}{k_{\text {national }}^{\text {ref }}}\right)^{-\beta_{c}}\left(\frac{k_{\text {regional }, t-1}^{\omega}}{k_{\text {regional }}^{\text {ref }}}\right)^{-\theta_{c}},
$$

where $I C_{c, t}^{\omega}$ denotes the investment cost, composed by the turbine cost $\left(T C_{c, t}^{\omega}\right)$ and the balanceof-system and soft costs $\left(B O S_{c}^{r e f}\right) . \quad \beta_{c}$ is a national learning exponent and $\theta_{c}$ a regional learning exponent, calibrated to replicate the observed diffusion paths (see subsection 5.1). $k_{\text {national, } t}^{\omega}$ represents the cumulative amount of installed capacity at year $t$ within country $c$ 's borders. $k_{\text {regional, } t}^{\omega}$ measures the cumulative installed capacities in the other European countries (EU-28). Hence we have $k_{t}^{\omega}=$ $k_{\text {national }, t}^{\omega}+k_{\text {regional }, t}^{\omega}$. Turbine costs $T C_{c, t}^{\omega}$ is a function that incorporates the effects of turbines scaling and metal prices whereas $B O S_{c}^{r e f}$ takes country-specific reference values that decrease with learning but remain unaffected by other factors.

The specification of $T C_{c, t}^{\omega}$ relies on several equivalence laws between a turbine's mass, its diameter and the corresponding rated power. These equivalences are detailed in Appendix B and allow to express $T C_{c, t}^{\omega}$ in euros $/ \mathrm{kW}$ as a function of turbine's rated power $C a p_{c, t}^{\omega}$. The turbine cost is written as

$$
T C_{c, t}^{\omega}=\left(\sum_{j=1}^{4} w_{j}\left(\frac{C a p_{c, t}^{\omega}}{C_{a p_{c}^{r e f}}^{r e f}}\right)^{3 / 2} I_{j, t}+w_{\text {other }}\left(\frac{C a p_{c, t}^{\omega}}{\operatorname{Cap}_{c}^{r e f}}\right)^{3 / 2}\right) T C_{c}^{r e f},
$$

with $C a p_{c}^{r e f}$ the initial value of turbine's rated power in country $c$ and $T C_{c}^{r e f}$ the corresponding cost (expressed in euros $/ \mathrm{kW}$ ). The influence of metals prices is captured by the price indexes $I_{j, t}$ that take unit values at the year of reference. Four metals are considered: aluminum, steel, iron and copper. Their weights in the turbine cost, denoted $w_{j}$, are calibrated based on their shares in the turbine mass; the conversion from the turbine's mass to its rated power is deduced from the equivalence relations evoked above. In fact, equation (9) applies a correcting factor to the reference value of the turbine cost that captures the effects of turbines scaling and metal prices.

Finally, Cost(.) is written as the discounted sum of all costs, assuming that the investment cost (8) is paid at the first period of operation and that other costs are discounted at rate $a_{c, t}$. Hence, it is written

$$
\operatorname{Cost}\left(\operatorname{Cap}_{c, t}^{\omega}, k_{t-1}^{\omega}\right)=I C_{c, t}^{\omega}+\sum_{i=0}^{T} \frac{Q_{c, t}^{\omega} O \& M}{\left(1+a_{c, t}\right)^{i}}
$$

where $O \& M$ denotes the operation and maintenance costs per unit of generated $\mathrm{kWh}$. Due to the lack of data on operation and maintenance costs, they are considered to be time invariant and equal among cohorts and countries. This assumption is made in order to reduce the uncertainty associated with arbitrary chosen country-specific values and the resulting distortions when comparing the levels of profitability. A value of 1.35 euro-cents per $\mathrm{kWh}$ is taken as representative because it corresponds to an average estimate based on German, Spanish, Danish and English experiences [47]. Annual amounts of generated electricity are denoted $Q_{c, t}^{\omega}$ and are assumed to be constant over the lifetime of a turbine. $Q_{c, t}^{\omega}$ intervenes both in Cost(.) through the $O \& M$ costs and in Revenue(.). The revenue part of the RoI is computed as the discounted sum of yearly revenue flows: 


$$
\text { Revenue }_{c, t}^{\omega}=\sum_{i=0}^{T} \frac{P_{c, t, i}^{\omega} Q_{c, t}^{\omega}}{\left(1+a_{c, t}\right)^{i}}
$$

where $P_{c, t, i}^{\omega}$ the average price at year $i$ paid to a producer of cohort $t$ per generated $\mathrm{kWh}$. This variable is affected by national demand-pull policies and/or electricity market conditions. The negative effect of turbines scaling on profitability has been incorporated in the Cost(.) function and a consistent representation should consider its positive effect on turbine's productivity. Again, equivalence laws between wind speed, turbine size and its rated power allow us to construct the yearly generated output as a function of turbine capacity. It is written:

$$
Q_{c, t}^{\omega}=Q_{c}^{r e f}\left(\frac{C a p_{c, t}^{\omega}}{C a p_{r e f}}\right)^{\frac{3}{2} \alpha}
$$

where $Q_{c}^{r e f}$ is the initial country-specific amount of annual output and $\alpha$ is the wind shear exponent. The latter represents the increase in wind speed velocity at higher altitude resulting from a lower effect of obstructions, e.g. buildings or trees. The wind shear exponent is assumed to be equal to one seventh as it corresponds to a smooth and grass-covered terrain. Deviations from these values are captured by the distribution around the level of profitability. To conclude, expected profitability $R o I_{c, t}^{\omega}$ is expressed as a function of turbine's rated power $\operatorname{Cap}_{c, t}^{\omega}$ when incorporating (11) in $\operatorname{Revenue}_{c, t}^{\omega}$ and Cost $_{c, t}^{\omega}$. It also depends on the cumulative installed capacity at $t-1$ because of the learning-by-doing. It is written

$$
\operatorname{RoI}_{c, t}^{\omega}=\frac{\operatorname{Revenue}\left(\operatorname{Cap}_{c, t}^{\omega}, k_{t-1}^{\omega}\right)-\operatorname{Cost}\left(\operatorname{Cap}_{c, t}^{\omega}, k_{t-1}^{\omega}\right)}{\operatorname{Cost}\left(\operatorname{Cap}_{c, t}^{\omega}, k_{t-1}^{\omega}\right)} .
$$

In this expression, the key variable is $C a p_{c, t}^{\omega}$. Data on turbines average rated power are available per year and country in the IEA Wind reports [45]. However, in counter-factual scenarios the average rated power for a cohort $t$ cannot be considered as exogenous as it depends from two factors:

- at the country level, the geographic and climatic peculiarities impact the optimal choice made by wind power plants designers about turbines rated power.

- at the European level, the progress made by manufacturers in producing larger wind turbines positively affects the value of $C a p_{c, t}^{\omega}$.

Consequently, the turbines rated power at time $t$ can be represented by a country-specific function of $k_{t-1}^{\omega}$ that approximates the experience gathered by wind turbines manufacturers in building larger units. The European cumulative capacity is chosen instead of the global one in order to exclude the experience gathered by foreign manufacturers, in particular the US and Chinese. According to the European Wind Energy Association, the global market shares of European turbine manufacturers was $37 \%$ in 2010 [42]. However, at the European level it rises to $89 \%$. Hence, the European market is a relevant measure of EU manufacturers experience and since $k_{t}^{\omega}$ is expressed relatively to the reference level $k_{r e f}$ the variation matters, not the absolute level. A functional form of the link between $C a p_{c, t}^{\omega}$ and $k_{t-1}^{\omega}$ that fits well the observed relations is 


$$
\operatorname{Cap}_{c, t}^{\omega}=d_{c}\left(\frac{k_{t-1}^{\omega}}{k^{r e f}}\right)^{b_{c}}
$$

where $b_{c}<1$ represents the elasticity of turbines rated power of country $c$ to European cumulative installed capacities. For each country this relation is estimated and the results are presented in the section B of the Appendix. The estimated coefficients are retained when simulating counter-factual scenarios. If suppressing demand-pull policies substantially reduces the diffusion of wind power in a country it will reduce the European cumulative installed capacity and, indirectly, it will reduce the average rated power of the newly built turbines. To summarize, the micro-founded model of diffusion determines the newly installed wind capacities per year for a particular country and consequently determines the value of $k_{t}^{\omega}$, that has two impacts on the variation of the profitability : (1) the learning effect that reduces the installed cost; (2) the growing turbine rated power that increases both the turbine cost and the generated amount of $\mathrm{kWh}$ per year. Thus, relation (13) links a period to the next and endogenously determines the diffusion dynamics.

\subsection{Sources of heterogeneity and national policies}

In this subsection the several types of heterogeneity synthesized by the $R o I_{c, t}^{\omega}$ are detailed. When necessary, precisions are given about the assumptions made for its computation. A complete description of the assumptions and the data used for computing $R o I_{c, t}^{\omega}$ is given in Appendix C.

The first source of heterogeneity is related to demand-pull policies. Among the six countries analyzed in this article, three types of demand-pull policies have been implemented:

- Feed-in tariff (FiT) is the most frequently policy instrument implemented for promoting renewable energy. It makes it compulsory for the system operator(s) to buy each kWh of renewable electricity at a fixed rate, independently of market signals. The tariffs are defined for a given period.

- Feed-in Premium (FiP) constitutes an alternative to the previous instrument. The principle is the same except that producers receive a fixed premium on top of the market price.

- Tradable Green Certificates (TGC) is a quantity-based instrument. It requires electricity suppliers to supply a certain amount of renewable electricity. In order to demonstrate that they have complied with quotas of renewable electricity, suppliers must present the corresponding quantity of certificates. For this purpose and for the sake of flexibility, a green certificates market is established and its price constitutes the support to renewable electricity producers (in addition to the market revenue).

Table 2 presents the successive phases of the demand-pull support policies implemented in the analyzed countries. A more detailed version of this Table is given in Appendix D. The RoI $I_{c, t}^{\omega}$ takes into account the national support policies through the values taken by $P_{c, t, i}^{\omega}$ in $O D^{\text {country }}$ scenarios.

The second source of heterogeneity is technological. First, investment costs are initialized with country-specific values from the IEA Wind national reports [45]. When the reports do not distinguish 


\begin{tabular}{|c|c|c|c|c|c|c|}
\hline & $\begin{array}{c}\text { Denmark } \\
(1985-2012)\end{array}$ & $\begin{array}{c}\text { France } \\
(2001-2012)\end{array}$ & $\begin{array}{c}\text { Italy } \\
(2000-2012)\end{array}$ & $\begin{array}{c}\text { Spain } \\
(2000-2012)\end{array}$ & $\begin{array}{c}\text { Portugal } \\
(2000-2012)\end{array}$ & $\begin{array}{c}\text { Germany } \\
(2000-2012)\end{array}$ \\
\hline FIT & $\begin{array}{c}\text { Phase } 1 \\
(1985-1990) \\
\text { Phase } 2 \\
(1991-1999) \\
\text { Phase } 3 \\
(2000-2002)\end{array}$ & $\begin{array}{c}\text { Phase } 1 \\
(2001-2005) \\
\text { Phase } 2 \\
(2006-2012)\end{array}$ & $\begin{array}{c}\text { Phase } 1 \\
(2000-2001)\end{array}$ & $\begin{array}{c}\text { Phase } 1 \\
(2000-2003) \\
\text { Phase } 2 \\
(2004-2006) \\
\text { Phase } 3 \\
(2007-2012)\end{array}$ & $\begin{array}{c}\text { Phase } 1 \\
(2000-2001) \\
\text { Phase } 2 \\
(2002-2004) \\
\text { Phase } 3 \\
(2005-2012)\end{array}$ & $\begin{array}{c}\text { Phase } 1 \\
(2000-2008) \\
\text { Phase } 2 \\
(2009-2012)\end{array}$ \\
\hline$\overline{\text { FIP }}$ & $\begin{array}{c}\text { Phase } 4 \\
(2003-2007) \\
\text { Phase } 5 \\
(2008-2012)\end{array}$ & & & $\begin{array}{c}\text { Phase } 1 \\
(2000-2003) \\
\text { Phase } 2 \\
(2004-2006) \\
\text { Phase } 3 \\
(2007-2012)\end{array}$ & & \\
\hline TGC & & & $\begin{array}{c}\text { Phase } 2 \\
(2002-2005) \\
\text { Phase } 3 \\
(2006-2012)\end{array}$ & & & \\
\hline
\end{tabular}

Table 2: Evolutions of demand-pull policies for onshore wind power in the six European countries analyzed.

the turbine cost from other costs the following decomposition is applied: turbine cost is assumed to represent $71 \%$ of the investment cost and balance-of-system and soft costs $29 \%$ [5]. Second, learningby-doing rates are country specific and capture how the countries convert the experience gathered at the European and national levels into lower investment costs.

The third source of heterogeneity is geographic, which is of special importance for variable energies. First, it is included in the analysis by using national capacity factors. Capacity factors are the ratio between the produced output per year and the maximum theoretical production. Based on Boccard [6], the capacity factors of a MW of wind power is computed for each country. These values are used to initialize the amount of generated output in each country. Then, capacity factors improve with turbines scaling as expressed by (11). Second, geographic peculiarities influence how power plants designers will adapt the optimal size of turbines. For instance, the increase of turbines size in Italy has been slower, compared to other countries such as Germany, in order to adapt the turbines to rough and hard-to-access terrain [45]. Estimates of the link between the turbines rated power and the cumulative European installed capacities capture this second type of geographic heterogeneity.

The last source of heterogeneity is economic. The economic background influences several parameters such as discount rates, estimated using a Capital Asset Price Model (see subsection C.4 of Appendix C), and electricity spot prices. The latter fulfills three functions in the analysis:

- In the case of Feed-in-Premiums and Tradeable Green Certificates, a share of producers revenues comes from the electricity market.

- After the scheme ends, if it does before the decommissioning of the plant, the producer only receives the market price.

- In the counter-factual scenarios, the only source of revenue are sales on the electricity spot market. This last point has been detailed in subsection 2 . 
These several sources of heterogeneity are included in the model in order to explain the paths of diffusion of wind power technology in six European countries. The diffusion is measured by the gross cumulative installed capacities. Indeed, using the net cumulative installed capacities would bias the measure of learning because it would only measure the difference between the total capacities that have been commissioned and those that have been decommissioned. The time series of gross cumulative installed capacities are constructed using several data sources. For Denmark, the data source is the Master Data Register of Wind Power. For Germany, Spain and Italy, the data on yearly installed capacities is from the IEAWind annual reports [45]. For France and Portugal, the data is from the website Thewindpower.net that lists all the wind sites that have been developed in these countries.

\section{Calibration and results}

\subsection{Calibration}

The purpose of the quantification of the parameters involved in (6) is to conduct a counter-factual analysis of the development of new onshore capacities for wind power by investigating several scenarios. As already stressed when commenting equation (6), parameter $\kappa$ is deduced from the other parameters so as to satisfy the initial condition (5). The parameters that must be calibrated are the initial level of average profitability $\mu_{0}$, the standard deviation $\sigma$ of the distribution of $R$, and the two learning exponents $\theta$ (European) and $\beta$ (national). The peculiarity of the counter-factual analysis is that we want to solve the dynamics in open loop, not in closed loop. Indeed, we want to construct a counterfactual time path of the proportion of installed capacities, starting from the same initial conditions than those that have actually prevailed, but proceeding with fictitious values of the revenue earned from wind electricity. For this purpose, we have to make sure that the values used for the parameters enable us to correctly reproduce the time path of wind power deployment in accordance with the actual values of the revenues determined by demand-pull policies. The open loop approach requires to compute the predicted proportion of installed capacities at dates $t>0$ on the basis of (6). If the dynamic equation (6) was linear, it could be done analytically and we would be able to estimate the parameters with standard econometric methods. The point is that (6) is highly non linear and that we are not able to find a simple and econometrically tractable analytical expression of $\Delta k_{t}$. Therefore, we calibrate the model rather than estimate it with econometric methods. Notwithstanding, we use a root mean square minimization method to calibrate the parameters. Indeed, a grid of possible values of the different parameters is first generated. For each set of parameters' values in the grid, we compute the time path of $k_{t}$ over the whole period of the study, conditionally on the initial condition (5), and on the observed values of the payments received by producers under support schemes. The set of parameters' values that minimizes the root mean square error (RMSE) between the simulated diffusion and its actual profile is used as the solution. A new minimization, based on a narrower grid with smaller increments between the values of parameters, is implemented until the RMSE obtained for the solution does not decrease more than a fixed relative value. A sensitivity analysis of our results to the parameters of the model is provided in Appendix E. Last but not least, prior to calibrating the parameters we need to specify a distribution function $f$ for $R$. For the sake of limiting the number of parameters, while 
allowing enough flexibility, we restrain the analysis to distributions with two parameters, a position parameter $\mu_{t}$ and a dispersion parameter $\sigma$. A natural candidate is the Gaussian distribution with expected value $\mu_{t}$ and standard deviation $\sigma$. An alternative specification for the distribution of $R$ is the Extreme Maximum Value distribution. This specification is an interesting alternative because it is initially defined for any real value of the return but, contrary to the Gaussian distribution, it is asymmetric. The distribution that generates the lower RMSE is retained in the counter-factual analysis. Parameters of the model are calibrated country by country. The results of calibration are given in Table 3.

\begin{tabular}{|c|c|c|c|c|c|c|c|}
\hline $\begin{array}{l}\text { Distribution } \\
\text { function } \\
\text { of the RoI }\end{array}$ & & $\mathrm{DE}$ & FR & IT & PT & $\mathrm{ES}$ & DK \\
\hline \multirow{5}{*}{ Gaussian } & $\mu_{0}$ & -12.92 & -8.52 & -11.36 & -7.8 & -3.83 & -1.35 \\
\hline & $\sigma$ & 12.12 & 1.99 & 3.91 & 2.37 & 2.8 & 0.2 \\
\hline & $\beta$ & 1.55 & 0.41 & 0.31 & 0.82 & 0.62 & 1 \\
\hline & $\theta$ & 2.27 & 4.8 & 1.69 & 2.25 & 2.31 & 0.28 \\
\hline & RMSE & $2.5872 * 10^{6}$ & 5582.02 & 136794 & 183199 & 430423 & 99898.9 \\
\hline \multirow{5}{*}{$\begin{array}{l}\text { Extreme } \\
\text { Values }\end{array}$} & $\mu_{0}$ & -13.7 & -4.62 & -32.15 & -17.45 & -2.89 & -0.89 \\
\hline & $\sigma$ & 13.4 & 0.77 & 1.11 & 1.08 & 2.71 & 0.38 \\
\hline & $\beta$ & 1.58 & 0.52 & 0.14 & 3.47 & 0.77 & 0.64 \\
\hline & $\theta$ & 2.27 & 4.78 & 1.62 & 2.4 & 2.36 & 0.55 \\
\hline & RMSE & $2.5818 * 10^{6}$ & 5036.99 & 83661.2 & 161098 & 419732 & 117520 \\
\hline
\end{tabular}

Table 3: Calibration results by country, depending on the distribution function of the RoI (ISO 3166-2 codes are used instead of countries complete names)

\subsection{Results}

\subsubsection{Observed Diffusion scenarios $\left(O D^{\text {country }}\right)$}

As explained in section 2 the first step of our analysis is to replicate as good as possible the diffusion paths of wind power that have been observed. Figure 3 represents for each country the observed and the replicated time paths of diffusion that integrate demand-pull policies. In order to visualize the Sshaped curves of diffusion the time period considered for all the countries is 1985-2012. It is the longer period for which data on investment cost is available and it corresponds to Denmark. The simulated time path starts later for the other countries (in 2000 for Germany, Spain, Italy and Portugal and in 2001 for France). The analyzed period ends in 2012 because Spain and Portugal have both ended their support schemes this year. Hence, extending the simulation period would bias the calibration of the model's parameters.

Several comments have to be made about the replicated diffusion paths of wind power, represented by the red lines on Figure 3. First, we can observe several jumps. This is the case for Germany (2010), Spain (2008), Italy (2006) and more generally for Denmark for which the replicated diffusion is subject to several jumps. For the three first countries two factors are responsible for these jumps. The first factor is the rise of the prices of metals that began around 2006 and that sees its maximum, during the analyzed period, in 2009 for aluminum, copper and steel. The higher level was reached later, in 2012 for iron. Even if we use a three years moving average of the prices of metals, we are not able to perfectly 

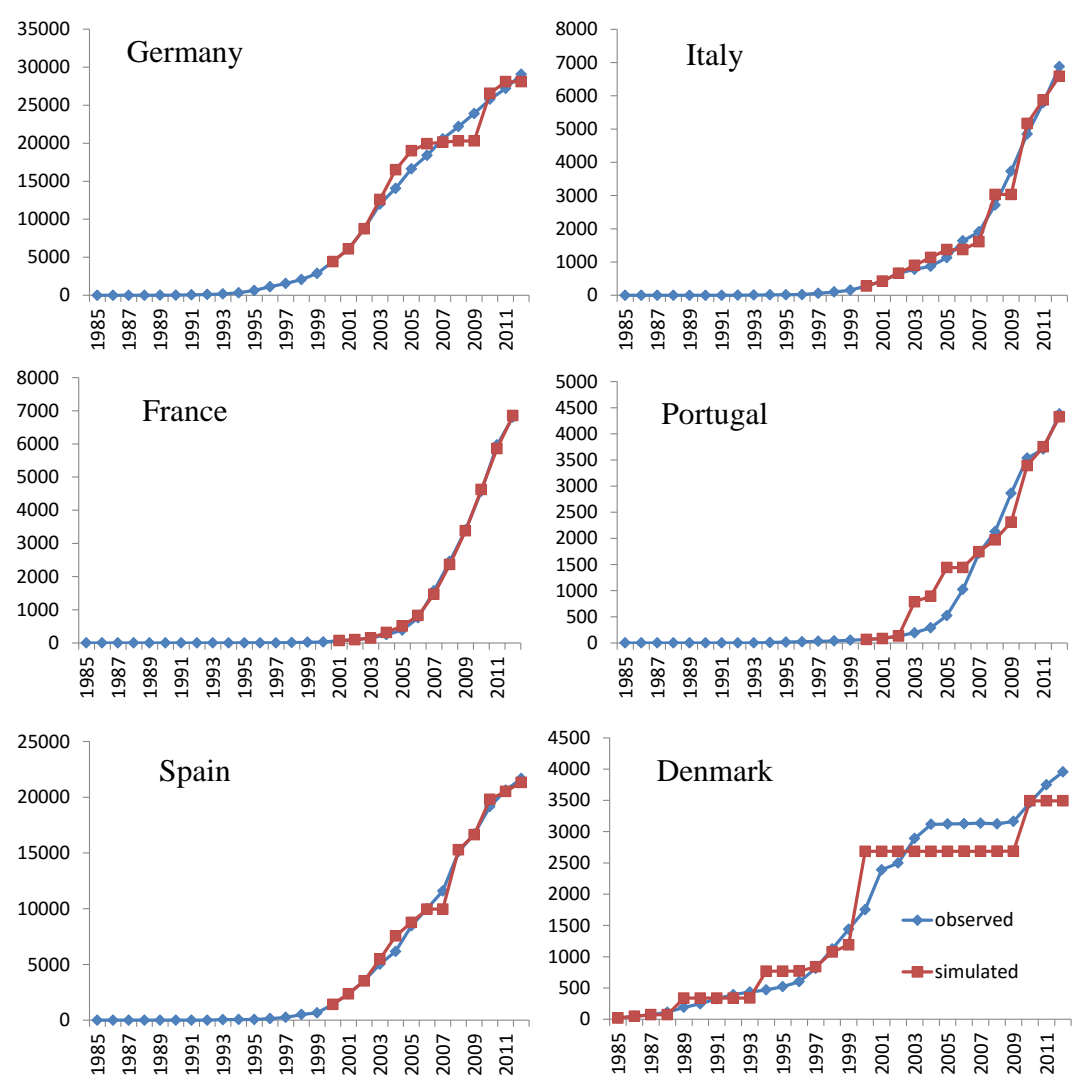

Figure 3: Observed (blue lines) versus replicated (red lines) time paths of diffusion of wind power (in cumulative MW of installed capacity).

represent how the manufacturers hedge themselves against the volatility of the cost of their inputs. Consequently, the negative effect of the rise of the metals prices indexes on profitability, and hence on diffusion, is exaggerated the years where a shock on metals prices occurred, until the replicated diffusion catches up the observed one. The second factor are the changes in national demand-pull policies. For these three countries the jumps in the replicated diffusion occur after a modification of the design of the demand-pull support, in each case it corresponds to an improvement of the conditions of support in terms of profitability through higher payments or longer support periods. In response to more attractive support policies the share of newly installed wind capacities rises within a year while in reality the administrative process associated with the installation of new renewable energy capacities tends to slow down the reaction to more advantageous policies in terms of newly installed capacities. The inability of the model to take into account the administrative process also explains the difference between the replicated and the observed diffusion in Portugal between 2003 and 2006. According to the IEA Wind reports [45], a critical effort has been made during these years, following the Dec.-Law no. $68 / 2002$, to simplify the administrative process concerning the implementation of renewable energy power plants. As it is neglected by the model, all the projects that are considered to be profitable are realized faster than in reality. Finally, for the Danish case the model is able to replicate the general 
trend of the diffusion but it is stair-shaped whereas the observed diffusion is smoother. The flat parts of the curve correspond to periods where no new wind sites should have been commissioned according to the model. However, the period of replication is much more longer than for the other countries and the replication of the general trend gives us confidence in the use of the model for the counter-factual analysis.

\subsubsection{Unilateral Removal scenarios ( $\left.U R^{\text {country }}\right)$}

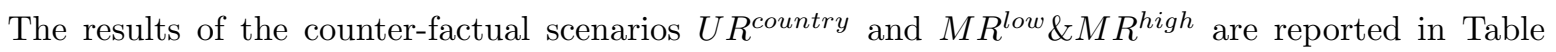
4. They are expressed as the percentage of difference between the amount of cumulative installed capacities of wind power in 2012 that the model replicates given the actual demand-pull policies and the amount of cumulative installed capacities induced by a suppression of the support scheme. In other words, the absolute values of the percentages given in this table are the shares of the national cumulative wind capacities that are imputable to demand-pull support policies, depending on the simulated scenario.

\begin{tabular}{cl|cccccc}
\hline \hline & & DE & FR & IT & PT & SP & DK \\
\hline$U R^{\text {country }}$ & Country of removal & $-36.99 \%$ & $-96.51 \%$ & $-88.41 \%$ & $-74.51 \%$ & $-49.24 \%$ & $-62.71 \%$ \\
& Other countries & $-21.68 \%$ & $-5.61 \%$ & $-5.2 \%$ & $-4.23 \%$ & $-16.08 \%$ & $-4.44 \%$ \\
\hline$M R^{\text {high }}$ & $-41.26 \%$ & $-96.9 \%$ & $-88.41 \%$ & $-83.53 \%$ & $-55.24 \%$ & $-68.79 \%$ \\
& $M R^{\text {low }}$ & $-42.09 \%$ & $-97.03 \%$ & $-88.41 \%$ & $-85.08 \%$ & $-56.35 \%$ & $-68.04 \%$ \\
\hline \hline
\end{tabular}

Table 4: Differences in \% of the cumulative capacities in 2012 between the counter-factual scenarios and the replicated scenarios with demand-pull support (simulations starts in 2001 and end in 2012).

Our counter-factual analysis of the unilateral removal of demand-pull policies allows us to identify two groups of country. The first group is composed of Germany and Spain and the second group gathers Italy, France and Portugal. Denmark exhibits a particular diffusion dynamics making a comparison with the other countries difficult; as discussed below it can be explained by an important modification of the support scheme occurring in 2008 and by the fact that diffusion has started earlier in this country. For the first group of countries we observe that removing the national support policies would have had a negative but moderate impact on the cumulative installed capacities of wind power in 2012. For instance, the German cumulative capacity would have been $36.99 \%$ lower and the same order of magnitude are found for Spain: $49.24 \%$. For these two countries the demand-pull policies contributed to accelerate the diffusion of wind technology. Nevertheless, simulated counter-factual time paths indicate that a slower but significant diffusion would have had occur anyway and in this sense the dynamics of diffusion is, of course, stimulated by demand-pull supports but also self-sustained by the effect of a national learning. These results suggest the existence of a first mover advantage that follows from an important role of the national learning and reduces the dependency of wind power diffusion at the national scale on foreign demand-pull policies. This last point is strengthened when simulating the multilateral removal scenarios, as detailed in the next part of the subsection.

The second group is composed by France, Portugal and Italy. The common denominator is the high negative impact of removing the demand-pull policies on the cumulative installed capacities. An unilateral removal of the demand-pull policies of these countries would have decreased the cumulative 
installed capacities by $96.51 \%, 88.41 \%$ and $74.51 \%$ for France, Italy and Portugal, respectively. For France and to a less extent Italy, the diffusion is almost fully imputable the policy support as only a very small amounts of wind capacities would have been installed in the absence of public support. For the three countries of this group the diffusion starts later compared to Germany, Denmark and Spain, preventing initial cost reductions that may trigger the diffusion dynamics.

One interesting property of the model is to measure how the diffusion dynamics of the six countries interact with each other through the European learning. It allows to estimate the impact of an unilateral removal on the five other countries. As can be expected the higher impacts are found for Spain and Germany; two countries with high levels of wind power installed capacities. For Germany, the removal of the demand-pull support would have decrease the cumulative installed capacities at the end of the diffusion period in the five other countries by $21.68 \%$. Spain also contributed to increase the European cumulative capacities as suppressing its demand-pull policy reduces by $16.08 \%$ the cumulative installed capacities in the five other countries. In this extent, Germany and Spain bear the cost of the scheme but contribute to generate important spillovers toward their European neighbors.
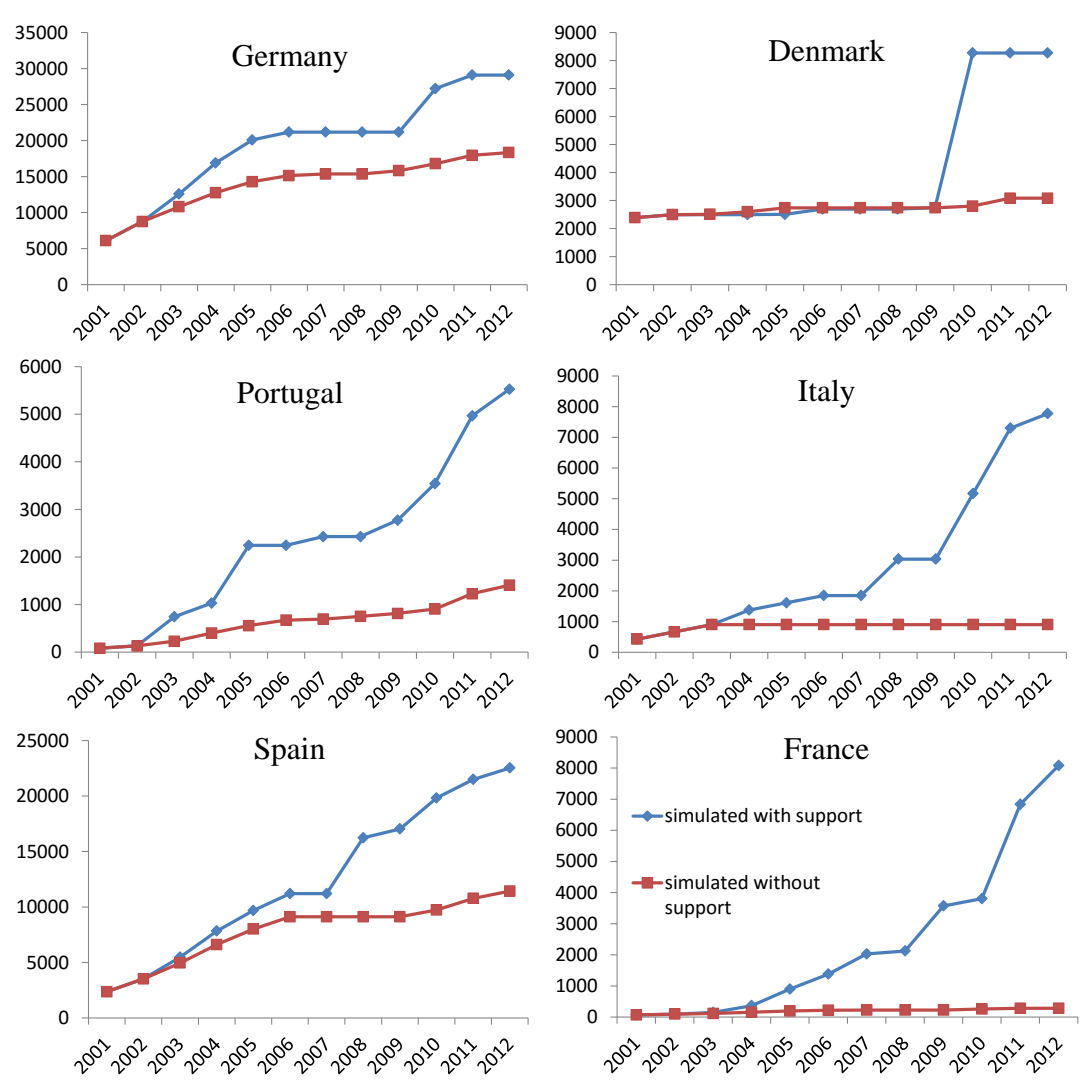

Figure 4: Simulated time paths of diffusion with and without demand-pull policies (in cumulative MW on installed power).

The detailed impact of unilateral removals through time are represented on Figure 4. The replicated diffusion time paths with demand-pull support are represented by the blue lines and the simulated 
diffusion without support by the red lines. Prior commenting this figure, it is worthwhile giving some precisions about how the diffusion time paths with demand-pull support are simulated. Compared to the diffusion time paths represented on Figure 3, the blue lines on Figure 4 are slightly different. Since we take into account the interactions between the six countries when investigating the unilateral removal of their policies, we do the same when simulating the diffusion time paths with the actual demand-pull policies. Hence, when simulating the supported diffusion, the newly built capacities in each country are jointly determined at each year and impact, through the regional learning, the other countries. To this extent, Figure 4 allows for a finer analysis of the impact of demand-pull support removal. A first remark is that for Spain and Denmark the impact of demand-pull support changes over time. For Spain, removing the support scheme has a relatively small impact on diffusion until 2007. Indeed, the diffusion simulated in the absence of demand-pull support is close to the diffusion obtained with support. The disconnection between the two diffusion paths occurs after 2007 when the feed-in premiums have been implemented as an option and chosen by $90 \%$ of producers [30]. This modification has been criticized for creating windfall profits but it seems that it has also strongly accelerated the diffusion of wind power in Spain. The same phenomenon is observed for Denmark as the demand-pull support impacts the diffusion only after 2009. Again, it may be explained by a modification of the form of the policy support. In Denmark, wind power producers were supported by a system of premium added to the spot price of electricity until 2008. The total payment was capped to 48 euros/MWh in order to reduce the windfall profits while reducing the volatility of the revenue. As we consider annual average values of the electricity spot price, this effect is excluded from our model. Since the average electricity price was close to the upper bound of the total payment the effect of the demand-pull support is underestimated before the scheme's reform. The suppression of this cap in 2008 has considerably improved the revenue from wind-generated electricity, as shows the jump in the diffusion process in 2009.

\subsubsection{Multilateral Removal scenarios $\left(M R^{l o w} \& M R^{h i g h}\right)$}

The impacts of a multilateral removal of demand-pull policies, expressed as the shares of the cumulative installed capacities in 2012 that would have not be installed due to the suppression of the demand-pull policies in the six countries are given in the two lower rows of Table 4 . The impact is detailed country by country. Consistent with the fact that an unilateral removal of their policies would have had a relatively small impact on their cumulative capacities compared to the other countries, Germany and Spain would have been less impacted by a multilateral removal. Nonetheless, the impact is slightly higher. The multilateral removal of demand-pull policies would have induced a decrease of the amount of cumulative installed capacities by approximately $41.5 \%$ in Germany and $55.5 \%$ in Spain in 2012, compared to the actual installed capacities. It should be kept in mind that our analysis focuses on six countries of the European Union and consequently, even when jointly removing their support policies, they continue to benefit from the learning in the other European countries. For Italy and France a multilateral removal of demand-pull policies almost prevents the diffusion of wind power to start but

the orders of magnitude stay comparable with the unilateral removal scenarios. Finally, an interesting result is the very low difference between the $M R^{\text {low }}$ and $M R^{\text {high }}$ scenarios indicating that the merit 
order effect has a limited impact. Hence, a lower share of wind electricity fed into the grid would have not been sufficient to raise the profitability of wind projects through higher electricity prices to induce a significant proportion of additional installed capacities. The two scenarios are presented on Figure 5 for each country.
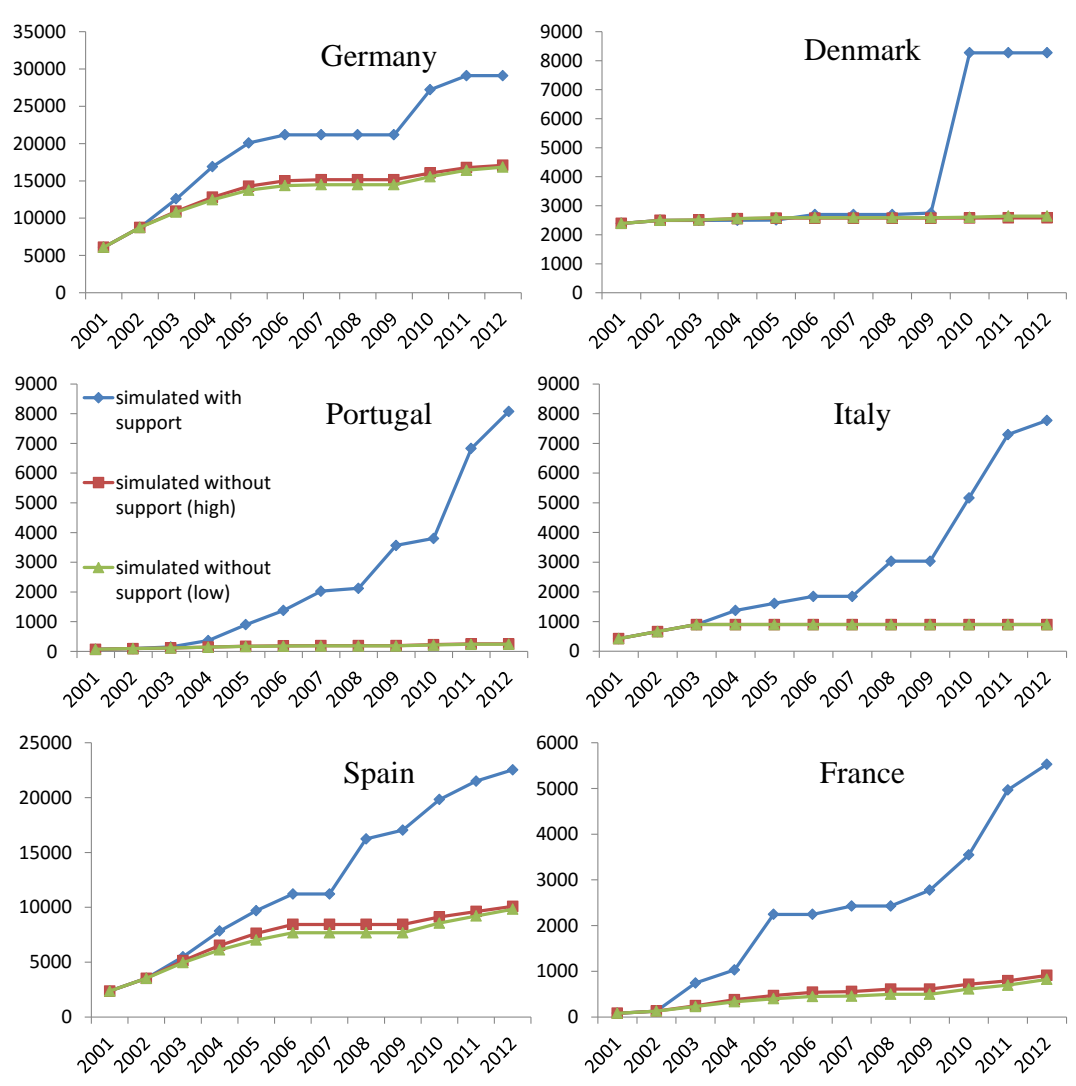

Figure 5: Simulated time paths of diffusion of the Multilateral Removal scenarios (in cumulative MW of installed power).

\section{Conclusion}

This paper presents a counter-factual analysis aiming at assessing the causal link between demandpull support instruments and the diffusion of wind power technology in six European countries. The results highlight the importance of distinguishing between the newly developed wind power capacities that are imputable to demand-pull instruments and those that would have been developed anyway. Moreover, the effect of demand-pull policies is very different from a country to another. In 2012, the shares of the cumulative installed wind power capacity that are imputable to the national demand-pull support policies vary between $37 \%$ and $96.6 \%$, depending on the country. By investigating several scenarios, it is shown that there are major spillovers effects between European countries. Germany and Spain have played important roles in the diffusion of wind power in Europe. Indeed, removing the 
demand-pull support policy in Germany or Spain, by reducing the installed capacity at the national level and consequently the learning spillovers, would have decreased the cumulative installed capacity at the year 2012 in the five other countries by $21.7 \%$ and $16 \%$, respectively. To this extent, there is an important cost borne by these two countries but it generates important positive spillovers for neighbor countries. The analysis of the scenarios suggests that the countries that have implemented at an early stage demand-pull support policies aiming at triggering the diffusion of wind power benefit from a firstmover advantage. This is the case for Germany and Spain where the diffusion of wind power is partially self-sustained in the sense that it has rather relied on cost reduction due to technological learning than on demand-pull policies. Moreover, it appears that this self-sustained diffusion does not result from technological learning in foreign countries, and thus from foreign demand-pull policies, since the joint removal of demand-pull policies in the six countries would not have strongly affected the diffusion of wind power in early-movers countries ${ }^{8}$. A rather similar result is found for Denmark as almost half of the diffusion resists to a suppression of the national demand-pull scheme. For Denmark however the interpretation should be made with cautious since the diffusion of wind power has started in this country at the end of the 1980s, whereas our simulation period starts in 2001. The idea that there is a first-mover advantage is reinforced by the laggards countries, i.e. the countries where the diffusion has started later. They are characterized by a high sensitivity of wind power diffusion to changes in the demand-pull support. Indeed, the removal of national demand-pull instruments in France, Italy and Portugal would have strongly reduced the diffusion of wind power technology in these countries. As can be expected, the negative impact on diffusion is further strengthened by a joint removal of demand-pull policies in the six countries but the gap with an unilateral removal however is rather small. This result highlights that a country cannot rely on foreign policies to stimulate the domestic diffusion of a new technology. These results lead to the conclusion that future demand-pull support policies targeting new renewable energy technologies would be improved by harmonizing the support schemes at the European level for two reasons. First, countries would not be tempted to adopt a freeriding strategy, i.e. not to implement a domestic demand-pull support policy while benefiting from spillovers due to technological learning induced by support policies implemented abroad. Our results suggest that there would be little to gain from such a free-riding strategy. Second, Europe will benefit from being a first-mover in supporting new renewable energy technologies as it will generate a partially self-sustained diffusion that will contribute to a large scale deployment of the supported technologies.

\section{References}

Academic literature.

[1] Bass, F. M., 1969. A new product growth for model consumer durables. Management science. 15, 215-227.

\footnotetext{
${ }^{8}$ Of course, these six countries do not represent the whole European wind power capacities. Nonetheless, they capture the majority of the European learning since they represented $89.43 \%$ of the European cumulative capacities of wind power in 2001, and $74 \%$ in 2012 (computation made based on the data of the EWEA).
} 
[2] Bass, F. M., 1980. The relationship between diffusion rates, experience curves, and demand elasticities for consumer durable technological innovations. Journal of business. 53, 551-567.

[3] Benhmad, F., Percebois, J., 2014. Wind power feed-in impacts on electricity system. Cahiers de recherche du CREDEN. 14.11.110.

[4] Brancucci Martinez-Anido, C., Brinkman, G., Hodge, B-M, 2016. The impact of wind power on electricity prices. Renewable Energy. 94, 474-487.

[5] Blanco, M.I., 2009. The economics of wind energy. Renewable and Sustainable Energy Reviews. $13,1372-1382$.

[6] Boccard, N., 2009. Capacity factor of wind power realized values vs. estimates. Energy Policy. 37, 2679-2688.

[7] Bolinger M., Wiser, R., 2012. Understanding wind turbine price trends in the U.S. over the past decade. Energy Policy. 42, 628-641.

[8] Cló, S., Cataldi, A., Zoppoli, P., 2015. The merit-order effect in the Italian power market: The impact of solar and wind generation on national wholesale electricity prices. Energy Policy. 77, 79-88.

[9] Cludius, J., Hermann, H., Matthes, F.C., Graichen, V., 2014. The merit order effect of wind and photovoltaic electricity generation in Germany 2008-2016: Estimation and distributional implications. Energy Economics. 44, 302-313.

[10] Coulomb, L., Neuhoff, K., 2006. Learning curves and changing product attributes: the case of wind turbines. Cambridge Working Papers in Economics. 0618.

[11] Chow, G. C., 1967. Technological change and the demand for computers. American Economic Review. 57, 1117-1130.

[12] Danchev, S., Tsakanikas, A., 2010. Returns on investment in electricity producing photovoltaic systems under de-escalating feed-in tariffs: the case of Greece. Renewable and Sustainable Energy Reviews. 14, 500-505.

[13] Ferioli, F., Schoots, K., van der Zwaan, B.C.C., 2009. Use and limitations of learning curves for energy technology policy: A component-learning hypothesis. Energy Economics. 37, 2525-2535.

[14] Gelabert, L., Labandeira, X., Linares, P., 2011. An ex-post analysis of the effect of renewables and cogeneration on Spanish electricty prices. Energy Economics. 33, S59-S65.

[15] Griliches, Z., 1957. Hybrid corn: an exploration in economics of technological change. Econometrica. $25,501-522$.

[16] Griliches, Z., 1980. Hybrid corn revisited: a reply. Econometrica. 48, 1463-1465. 
[17] Hirth, L., 2013. The market value of variable renewables, the effect of solar wind power variability on their relative price. Energy Economics. 38, 218-236.

[18] Hitaj, C., Schymura, M., Loeschel, A., 2014. The impacts of feed-in tariffs on wind power development in Germany. Discussion paper of the ZEW. 14-035.

[19] Jenner, S., Groba, F., Indvik, J., 2013. Assessing the strength and effectiveness of renewable electricity feed-in tariffs in European Union countries. Energy Policy. 52, 385-401.

[20] Kemp, R., 1998. The diffusion of biological wasterwater treatment plants in the Dutch food and beverage industry. Environmental and resource economics. 12, 113-136.

[21] Ketterer, J., 2014. The impact of wind power generation on the electricity price in Germany. Energy economics. 44, 270-280.

[22] Lindman, Ȧ., Söderholm, P., 2012. Wind power learning rates: A conceptual review and metaanalysis. Energy Economics. 34, 754-761.

[23] Luthi, S., Prassler, T., 2011. Analyzing policy support instruments and regulatory risk factors for wind energy deployment- a developers' perspective. Energy Policy. 39, 4876-4892.

[24] Mansfield, E., 1961. Technological change and the rate of imitation. Econometrica. 29, 741-766.

[25] Marques, A.C., Fuinhas, J.A., 2011. Drivers promoting renewable energy: A dynamic panel approach. Renewable and Sustainable Energy Reviews. 15, 1601-1608.

[26] Marques, A.C., Fuinhas, J.A., 2012. Are public policies towards renewable successful? Evidence from European countries. Renewable Energy. 44, 109-118.

[27] Mercure J.-F., Pollitt, H., Chewpreecha, U., Salas, P., Foley, A.M., Holden, P.B., Edwards, N.R., 2014. The dynamics of technology diffusion and the impacts of climate policy instruments in the decarbonisation of the global electricity sector. Energy Policy.73, 686-700.

[28] Mir-Artigues, P., Del Rio, P., 2014. Combining tariffs, investment subsidies and soft loans in a renewable electricity deployment policy. Energy Policy. 69, 430-442.

[29] Mulder, A., 2008. Do economic instruments matter? Wind turbines investments in the EU(15). Energy Economics. 30, 2980-2991.

[30] Ragwitz, M., Winkler, J., Klessmann, C., Gephart, M., Resch, G. 2012. Recent developments of feed-in systems in the EU-A. Research paper for the international Feed-in Cooperation. 16 pp.

[31] Sensfuß, F., Ragwitz, M., Genoese, M., 2008. The merit-order effect: A detailed analysis of the price effect of renewable electricity generation on spot market prices in Germany. Energy Policy. 36, 3086-3094.

[32] Sovacool, B., 2013. Energy policymaking in Denmark: Implications for global energy security and sustainability. Energy Policy. 61, 829-839. 
[33] Usha Rao, K., Kishore, V.V.N., 2010. A review of technology diffusion models with special reference to renewable energy technologies. Renewable and sustainable energy reviews. 14, 1070-1078.

[34] Zachmann, G., Peruzzi, M., 2014. When and how to support renewables? Letting the data speak. Bruegel working paper.

Books and Chapters.

[35] Burton, T., Sharpe, D., Jenkins, N., Bossanyi, E., 2001. Conceptual design of horizontal-axis turbines, in: Wind Energy Handbook. John Wiley \& Sons, LTD.

[36] Dinica, V., 2002. Renewable energy policies in Spain, in: Handbook of Renewable Energy in the European States-Case studies of all Member States. Frankfurt am Main: Peter Lang Publishing Group.

[37] Greene, W.H.,2011. Econometric analysis, 7th edition. Pearson Education.

Reports and non-academic studies.

[38] Agence De l'Environnement et de la Maîtrise de l'Enérgie. Premieres conclusions tirées de l'analyse économiques des projets éoliens en terre et en mer. November 2011.

[39] Carbon Trust. Analysis on policy frameworks to drive future investment in near and long-term renewable power in the UK. Policy frameworks for renewables. 2006.

[40] Commission de Régulation de l'Enérgie. Coûts et rentabilité des énergies renouvelables en France métropolitaine. April 2014.

[41] De Jager, D., Rathmann, M., 2008. Policy instruments design to reduce financing costs in renewable energy technology projects. ECOFYS. 2008.

[42] European Wind Energy Association, 2012. Green growth-the impact of wind energy on jobs and the economy.

[43] GHK, 2006. Strategic evaluation on environment and risk prevention under structural and cohesion funds for the period 2007-2013. National Evaluation Report for Portugal: Main Report.

[44] IEA, 2010. Projected costs of generating electricity. IEA/OECD.

[45] IEA Wind, 1978-2013. Annual Reports. IEA/EWEA/CWEA.

[46] IRENA-GWEC, 2012. 30 years of policies for wind energy, lessons from 12 wind energy markets.

[47] EWEA, 2009. The economics of wind energy, A report by the European Wind Energy Association. p. 45.

[48] European Renewable Energy Council, 2004. Renewable energy policy review: Germany.

[49] European Renewable Energy Council, 2009. Renewable energy policy review: Italy. 
[50] Intergovernmental Panel on Climate Change, 2012. Special Report of the Intergovernmental Panel on Climate Change, Renewable energy sources and climate change mitigation.

[51] U.S. department of energy, 2010. 2010 Wind technologies market report.

\section{A Appendix A: The return-on-investment function}

This appendix contains the Table 5 that presents the list of the variables used in the body of the article.

\section{B Appendix B: The return-on-investment function}

The average Return-on-Investment, $R o I_{c, t}^{\omega}$, in country $c$ for the cohort of wind plants commissioned at year $t$ is expressed as

$$
\operatorname{RoI}_{c, t}^{\omega}=\frac{\operatorname{Revenue}\left(k_{t-1}^{\omega}\right)-\operatorname{Cost}\left(k_{t-1}^{\omega}\right)}{\operatorname{Cost}\left(k_{t-1}^{\omega}\right)},
$$

where $k_{t-1}$ is the cumulative installed capacity of wind power in Europe (EU-28) at $t-1$. All variables that change with the scenario are indexed by $\omega$. This Appendix details how Revenue(.) and Cost(.) are constructed as functions of $k_{t-1}^{\omega}$. Advantages of making $R o I_{c, t}^{\omega}$ a function of the European cumulative capacity are discussed further in subsection 4.2.

\section{B.1 The Revenue Function}

$\operatorname{Revenue}\left(k_{t-1}^{\omega}\right)$ is the discounted sum of the yearly revenue of one MW of wind capacity installed at time $t$ in country $c$. It is computed as

$$
\operatorname{Revenue}_{c, t}\left(k_{t-1}^{\omega}\right)=\sum_{i=0}^{T} \frac{P_{c, t, i}^{\omega} Q_{c, t}^{\omega}}{\left(1+a_{c, t}\right)^{i}} .
$$

where $T$ is the power plant lifetime, $a_{t}$ the discount rate, $P_{c, t, i}^{\omega}$ the average annual price of electricity (in eurocents $/ \mathrm{kWh}$ ) during the year $i$ for the cohort $t$ and $Q_{c, t}^{\omega}$ the annual amount of generated kWh. Prices are taken as exogenous by producers and they are impacted by the policy support. Yearly amounts of generated output depend on national wind resources and on turbines' diameter. The latter factor is a key element because a substantial increase in turbines' size has been observed since technology started to diffuse and it has strongly improved wind plants' productivity. It is known that, ceteris paribus, the energy captured by a wind turbine scales with the cube of the wind speed:

$$
\frac{Q_{i}^{\omega}}{Q_{\text {ref }}}=\left(\frac{S^{\omega}}{S_{\text {ref }}}\right)^{3}
$$

where $S^{\omega}$ measures the mean wind speed that depends on the tower's height. $Q_{r e f}$ and $S_{r e f}$ are the reference values of generated output and mean wind speed, respectively. As done in Burton et 


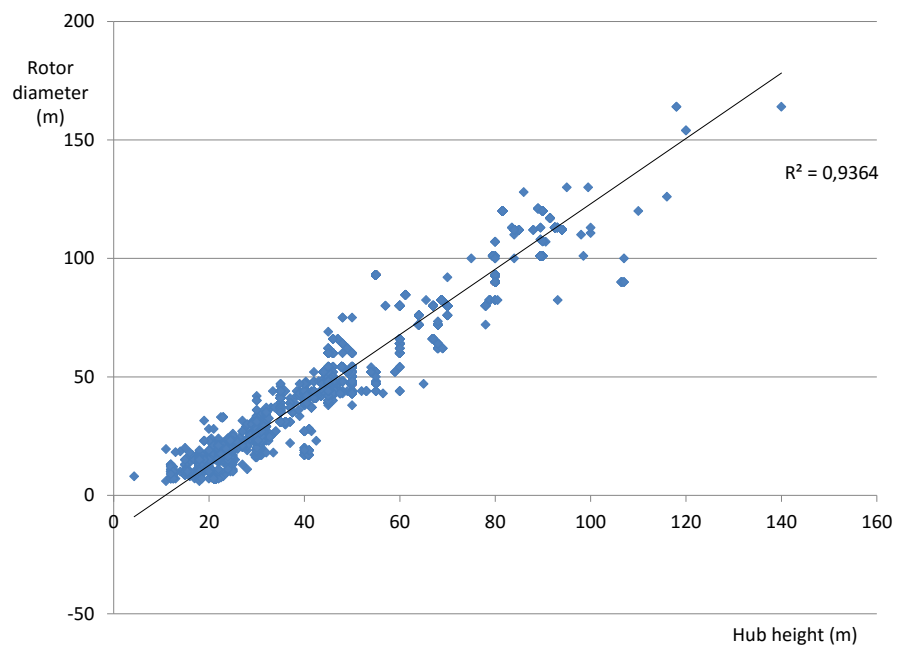

Figure 6: Correlation between turbine's height and rotor diameter, based on a sample of 8334 Danish turbines (from the Master Data Register of Wind Power).

al. [35] and Coulomb and Neuhoff [10] and supported by the correlation represented on Figure 6, the proportionality between a turbine height and its diameter is assumed. Moreover, the relation between the mean wind speed and the turbine size is approximated by an exponential function.

The mean wind speed variation is a function of turbine's height $(H)$, and thus of its diameter $(D)$ given the proportionality:

$$
\frac{S^{\omega}}{S_{\text {ref }}}=\left(\frac{H^{\omega}}{H_{\text {ref }}}\right)^{\alpha}=\left(\frac{D^{\omega}}{D_{\text {ref }}}\right)^{\alpha}
$$

with $D_{\text {ref }}$ and $H_{r e f}$ the reference values ([35]; [10]). $\alpha$ is the wind shear exponent measuring how mean wind speed increases with tower height. Given that energy scales with the cube of mean wind speed using (15) we can write how quantity scales with the diameter:

$$
\frac{Q_{i}^{\omega}}{Q_{r e f}}=\left(\frac{D^{\omega}}{D_{r e f}}\right)^{3 \alpha}
$$

Finally, the link is made with the installed capacity of the turbine, denoted $C a p_{c, t}^{\omega}$, as it scales with the square of the diameter ([42]). Thus

$$
Q_{i}^{\omega}=Q_{r e f}\left(\frac{C a p_{i}^{\omega}}{C a p_{\text {ref }}}\right)^{\frac{3}{2} \alpha} .
$$

To conclude, Revenue Ret $_{t}\left(k_{t-1}^{\omega}\right)$ depends only on the average rated power Cap $_{i}^{\omega}$ of the representative wind turbine and some parameters. The link with $k_{t-1}$ is made explicit below. 


\section{B.2 The Cost function}

Cost $_{c, t}^{\omega}$ is the sum of the discounted costs and can be decomposed into two components: investment cost, denoted $I C_{c, t}^{\omega}$, and operation and maintenance cost per generated $\mathrm{kWh}$ denoted $O \& M$. The former is assumed to be paid entirely on the first period so that

$$
\operatorname{Cost}_{c, t}^{\omega}=I C_{c, t}^{\omega}+\sum_{i=0}^{T} \frac{O \& M Q_{c, t}^{\omega}}{\left(1+a_{t}\right)^{i}} .
$$

As explained in the body of the article, $O \& M$ cost are assumed to be constant for every country and cohort. $I C_{c, t}$ is disaggregated into two components: the turbine cost $\left(T C_{c, t}\right)$ and the balance-ofsystem and soft costs $\left(B O S_{c}^{r e f}\right)$. As made for the Revenue function, $T C_{c, t}$ is expressed as a function of turbine's installed power. Ceteris paribus, the turbine's cost scales with its mass. Nonetheless, the analysis takes place in a dynamic framework and the factors that contributed to the observed increase in turbine prices during the late 2000s have to be incorporated. According to Bolinger and Wiser [7], the major factors are metal prices and turbine scaling. In order to include metal prices, the variation of $T C_{c, t}$ is decomposed as

$\frac{T C_{c, t}}{T C_{\text {ref }}}=w_{\text {steel }} \frac{m^{\omega}}{m_{\text {ref }}} I_{\text {steel }, t}+w_{\text {copper }} \frac{m^{\omega}}{m_{\text {ref }}} I_{\text {copper }, t}+w_{\text {iron }} \frac{m^{\omega}}{m_{\text {ref }}} I_{\text {iron }, t}+w_{\text {alu }} \frac{m^{\omega}}{m_{\text {ref }}} I_{\text {alu }, t}+w_{\text {other }} \frac{m^{\omega}}{m_{\text {ref }}}$

where the $w_{j}$ denote the shares of the turbine mass $\left(m^{\omega}\right)$ of metals and other components. The weights are assumed to be constant over time. Metal prices indexes, denoted by $I_{j, t}$, are introduced to represent the evolutions of metal prices over time and they take unit values for the reference year. A common approximation of the relation between turbine mass and its diameter is known as the cube law [35] and stipulates that the mass scales with the cube of turbine's diameter, so that we can write

$$
\frac{T C_{c, t}}{T C_{r e f}}=\left(\sum_{j=1}^{4} w_{j}\left(\frac{D^{\omega}}{D_{r e f}}\right)^{3} I_{j, t}+w_{\text {other }}\left(\frac{D^{\omega}}{D_{\text {ref }}}\right)^{3}\right) .
$$

As done for the Revenue function, using the relation according to which installed power scales with the square of diameter, the turbine cost is expressed as a function of turbine installed capacity

$$
T C_{c, t}=\left(\sum_{j=1}^{4} w_{j}\left(\frac{C a p^{\omega}}{C a p_{r e f}}\right)^{3 / 2} I_{j, t}+w_{\text {other }}\left(\frac{C a p^{\omega}}{C a p_{r e f}}\right)^{3 / 2}\right) T C_{r e f} .
$$

The second component, $B O S_{c}^{r e f}$ is difficult to model as its determinants are less documented. It is assumed that its values depend from both regional and national learning-by-doing effects impacting the whole investment cost. Hence, investment cost dynamics is initialized with observed reference values and formalized as

$$
I C_{c, t}=\left(T C_{c, t}^{\omega}+B O S_{c}^{r e f}\right)\left(\frac{k_{n a t i o n a l, t-1}^{\omega}}{k_{\text {national }}^{\text {ref }}}\right)^{-\beta_{c}}\left(\frac{k_{\text {regional }, t-1}^{\omega}}{k_{\text {regional }}^{\text {ref }}}\right)^{-\theta_{c}}
$$


where $\beta_{c}$ and $\theta_{c}$ are the learning-by-doing elasticities. Finally, the complete form of $\operatorname{Cost}_{c, t}^{\omega}$ is obtained by incorporating (18) in (16). At this stage, $R_{o} I_{c, t}^{\omega}$ is constructed as a function of $C a p_{c, t}^{\omega}$ the average capacity of wind turbines built at year $t$. National time series of $C a p_{c, t}^{\omega}$ are available and it would be possible to use it to estimate the parameters of the model. However, it could not be assumed that these values would have been the same when simulating the counter-factual scenarios because bigger wind turbines were available due to the technical progress made in manufacturing. In this sense, the average rated power of wind turbine at time $t$ is modeled as a function of the European cumulative capacity, $k_{t-1}^{\omega}$, and country-specific estimations are made on the basis of data on historical average wind turbine rated power, available in the IEAwind annual reports [45]. Results of these estimates are given on Figure 7.

\section{Appendix C: Assumptions and data}

\section{C.1 Investment Costs (IC)}

According to the IPCC [50], $I C_{t}$ for an onshore wind plant encompasses the turbine cost, grid connection costs, civil work costs and other costs (transaction costs, land cost, etc.). The cost values used for initializing the dynamics of diffusion come from the IEAwind annual reports [45], except for France where it come from [38]. They are summarized in Table 6. Stars indicate the countries for which, in the absence of available data, a decomposition of the investment cost is applied following Blanco [5]: $71 \%$ for the turbine cost and $29 \%$ for the balance-of-system and soft costs.

\section{C.2 Operation and Maintenance Costs (O\&M)}

O\&M costs gather insurance costs, management costs, repair and replacement costs. However, depending on studies, all or parts of these costs are taken into account. In order to avoid any bias when comparing countries, the choice is made to use the same value for the six countries. Based on [47], a value of 1.35 euro-cents per $\mathrm{kWh}$ is chosen.

\section{C.3 National capacity factors}

Assumptions about the capacity factor of a wind turbine may vary significantly from a study to another. In this article, the retained values are from Boccard [6] who computes the realized values of the wind power capacity factors for several European countries. They are reported in Table 7 . The initial levels of generated output are computed on the basis of these capacity factors.

\section{C.4 Discount rates}

The $R o I_{c, t}^{\omega}$ is computed using country and year specific risk-adjusted discount rates. These are produced with a Capital Asset Pricing Model described by the following equation

$$
E\left[r_{c, t}^{i}\right]=r f_{t}+\beta \pi_{c, t}
$$


where $E\left[r_{c, t}^{i}\right]$ is the expected rate of return of an asset at year $t$ in country $i, r f_{t}$ the risk-free rate and $\pi_{c, t}$ the market risk premium. The $\beta$ coefficient is the usual measure of the systematic risk and it is calibrated using the average beta of a group of representative European electricity companies. These firms and their respective betas are presented in Table 8 .

For each company, the beta is estimated by regressing the company's return on the return of its benchmark market. Data on electricity companies and market returns are from the Datastream database. Based on these estimates, the retained value for the $\beta$ in equation (19) is 0.77. In order to compute the discount rates, equal to $E\left[r_{c, t}^{i}\right]$, we need two additional inputs: the risk-free rate and the country market premium. The risk-free rate is approximated by the annualized Eonia interest rate. Country-specific market risk premiums are computed using the annual average market risk premiums for the countries we study, retrieved from the website Fenebris.com. As the market risk premium is not available for Portugal, we assume that it is the same than for Spain. The time path of the resulting discount rates are displayed on the Figure 8.

\section{C.5 Electricity Prices}

The liberalization of electricity markets in Europe that began in the 2000s produced an increasing amount of information. Data on the electricity spot price is used whenever it is available. Otherwise, assumptions on the electricity price are made. Sources and assumptions are detailed in this subsection.

\section{Denmark}

The Danish system operator (dk.net) provides data for hourly spot price on DK-west and hourly wind generation since 2003. Prices used are the yearly average price weighted by the wind output. Before 2003 and after 2012 we assume a yearly spot price equals to $50 € / \mathrm{MWh}$.

\section{Germany}

Before 2005, we assume a spot price of $30 € /$ MWh. Based on data from EPEX between 2005 and 2011, yearly average spot prices are calculated. After 2011, we assume a spot price of $49 € / \mathrm{MWh}$.

\section{France}

In France, since $77 \%$ of the generated electricity come from nuclear technology the chosen value for the spot price is the price of the Regulated Access to the Historical Nuclear Electricity, i.e. $42 € /$ MWh. Even if this value was defined in 2010, it is a good approximation of the cost of nuclear electricity that represents the main competitor for wind power.

\section{Italy}

Before 2005, IEA Wind reports on Italy provided the yearly average market revenue of wind producers, a useful information for the RoI computation. Between 2005 and 2012 the system operator (Gestore Mercati Energetici) makes available data on hourly spot price. Yearly averages are used. After 2012, a spot price equals to $60 € / \mathrm{MWh}$ is assumed. 


\section{Portugal}

Fom 2000 to 2006 regulated tariffs are integrated in RoI. After 2006 yearly average spot prices are used, from the OMEL (Operador del mercado Energéticos). Then after 2012, an assumption of 50 $€ / \mathrm{MWh}$ is made.

\section{Spain}

Since 2000 the OMEL communicates price data. Due to the strong convergence between Spanish and Portuguese markets, the same assumption is made about the future spot price of electricity.

\section{C.6 Metals weights and price}

In this paper, it is assumed for simplicity that metals weights are constant over time. For calibration, the values we choose correspond to the average shares of metals for four types of wind turbines presented on Table 9 .

\section{Appendix D: Evolution of the demand-pull schemes in the six European countries}

Table 10 presents the several phases of the analyzed demand-pull policies.

\section{E Appendix E: Sensitivity analysis}

A sensitivity analysis of results with respect to parameters is conducted. It proceeds in the following steps. First, the difference in terms of installed capacities between the replicated diffusion path and the counter-factual one (in the $U R^{\text {country }}$ cases) is computed for each year $t$ from 2001 to 2012 in each country $c$. The difference in terms of installed capacities is denoted $\Delta_{t}^{c}$. Second, this exercise is repeated but with one of the parameter increased by $1 \%$. It is denoted $\bar{\Delta}_{t}^{c}$. Third, in order to capture the sensitivity of the simulations to the model's parameters these two differences are compared relatively to the installed capacities as computed for the current year in the replicated diffusion path using the parameters initially calibrated. The installed capacities in country $c$ at year $t$ is denoted

\footnotetext{
${ }^{1}$ The sources for Denmark are [45], [32], [29] and [46].

${ }^{2}$ Royal Decree 2818/1998 gives the choice to producers between a FiT and a FiP. Since 'an overwhelming majority of RES plant owners chose the market-based price option', according to [36], only the premium option is considered for the $I R$ index computing.

${ }^{3}$ According to the Royal Decree 2818/1998, the FiT is guaranteed for five years. However, it contains a provision guarantying unlimited availability of premiums and therefore, indirectly, automatic renewal of purchase contracts [36]. A survey conducted among 40 renewable energy producers demonstrated the minor role of the uncertainty on purchase contracts renewal [36].

${ }^{4}$ The Average Electricity Tariff (AET) reflects the overall average cost of the electricity system. The level of the AET is decided each year by the government, values can be found in national reports on Spain [45].

${ }^{5}$ To compute the $I R$ index, the premium option is retained since $90 \%$ of wind producers have opted for the FIPsupport' according to [30].

${ }^{6} \mathrm{Cap}$ and floor prices are indexed on the electricity retail price. In 2008 , the values were $73.6 € \mathrm{MWh}$ and $87.8 € \mathrm{MWh}$.

${ }^{7}$ According to the Royal Decree 1614/2010.
} 
$M W_{t}^{c}$. The average values are retained to obtain a measure of the sensitivity. More formally, it is written

$$
\text { Sensitivity }=\frac{1}{12} \sum_{t=2001}^{2012}\left[\frac{\left(\bar{\Delta}_{t}^{c}-\Delta_{t}^{c}\right)}{M W_{t}^{c}}\right]
$$

In Table 11, the values of Sensitivity for each country and parameter are given. The case for a negative shock, i.e. $-1 \%$, is also investigated.

A low sensitivity of the simulations to the parameters that are not calibrated or estimated (i.e. $q, t$, $O \& M$ and $B O S_{c}^{r e f}$ ) is observed, which is a good point. As can be expected, simulations are generally more sensitive to the parameters for Italy, France and Portugal. It can be explained by the fact that the diffusion of wind power in these countries strongly depends from their demand-pull policies. Finally, two major parameters are those of the distribution of the profitability, $\sigma$ and $\mu_{0}$, in the sense that the model is more sensitive to their values. Because investment decisions are made based on a profitability criteria, this sensitivity to the parameters of the distribution is expected to occur. To this extent, a precise calibration based on the minimization of the RMSE, as it is done in this paper, strengthens the validity of our results. 


\begin{tabular}{|c|c|}
\hline Variables & Description \\
\hline$\mu_{t}$ & $\begin{array}{l}\text { Position parameter of the distribution of the profitability } \\
\text { of wind power units (MW) in a country at time } t \text {. }\end{array}$ \\
\hline$\sigma$ & $\begin{array}{l}\text { Standard deviation of the distribution of the profitability } \\
\text { of wind units in a country. }\end{array}$ \\
\hline$\kappa_{\max }$ & Total potential of wind power in a country. \\
\hline$\Delta \kappa_{t}$ & Amount of newly developed wind power units at time $t$. \\
\hline$\kappa_{0}$ & $\begin{array}{l}\text { Initial, i.e. at the beginning of the simulation period, cumulative } \\
\text { wind power capacity in a country. }\end{array}$ \\
\hline $\operatorname{RoI} I_{c, t}^{\omega}$ & $\begin{array}{l}\text { Benchmark level of profitability of a wind unit at time } t \\
\text { in the country } c \text { in the scenario } \omega \text {. }\end{array}$ \\
\hline$I C_{c, t}^{\omega}$ & $\begin{array}{l}\text { Investment cost (euros } / \mathrm{kW} \text { ) at time } t \text {, in the country } c \\
\text { in the scenario } \omega \text {. }\end{array}$ \\
\hline$T C_{c, t}^{\omega}$ & $\begin{array}{l}\text { Turbine cost (euros } / \mathrm{kW}) \text { at time } t \text {, in the country } c \\
\text { in the scenario } \omega \text {. }\end{array}$ \\
\hline$T C_{c}^{r e f}$ & Initial turbine cost (euros $/ \mathrm{kW})$ in the country $c$. \\
\hline$B O S_{c}^{r e f}$ & Balance-of-system and soft costs in the country $c$. \\
\hline & National learning exponent of the country $c$. \\
\hline$\theta_{c}$ & Regional learning exponent of the country $c$. \\
\hline$C a p_{c, t}^{\omega}$ & $\begin{array}{l}\text { Average turbine's rated power at time } t \text {, in the country } c \\
\text { in the scenario } \omega \text {. }\end{array}$ \\
\hline $\operatorname{Cap}_{c}^{r e f}$ & Initial average turbine's rated power in the country $c$. \\
\hline$I_{j, t}$ & Index of the price of the metal $j$ at time $t$. \\
\hline$w_{j}$ & Share of the metal $j$ in the total weight of a turbine. \\
\hline$O \& M$ & Operation and maintenance costs. \\
\hline$a_{c, t}$ & CAPM-based discount rates in the country $c$ at time $t$. \\
\hline$Q_{c, t}^{\omega}$ & $\begin{array}{l}\text { Annual output of a wind unit developed at time } t \text { in the } \\
\text { country } c \text { in the scenario } \omega \text {. }\end{array}$ \\
\hline$P_{c, t, i}^{\omega}$ & $\begin{array}{l}\text { Average price at time } i \text { per unit of output generated by a } \\
\text { wind unit developed at time } t \text { in the country } c \text { in the scenario } \omega \text {. }\end{array}$ \\
\hline$\alpha$ & Wind shear exponent. \\
\hline$d_{c}$ & $\begin{array}{l}\text { parameter of the relation between the turbine's rated power in } \\
\text { the country } c \text { and the cumulative European installed capacity. }\end{array}$ \\
\hline$b_{c}$ & $\begin{array}{l}\text { elasticity of turbine's rated power in the country } c \text { and the } \\
\text { cumulative European installed capacity. }\end{array}$ \\
\hline
\end{tabular}

Table 5: List of the variables of the model.

\begin{tabular}{ccccccc}
\hline \hline & $\mathrm{DK}^{*}$ & $\mathrm{DE}$ & $\mathrm{FR}^{*}$ & $\mathrm{IT}^{*}$ & $\mathrm{ES}$ & $\mathrm{PT}^{*}$ \\
& $(1985)$ & $(2000)$ & $(2001)$ & $(2000)$ & $(2000)$ & $(2000)$ \\
\hline$T C_{c}^{r e f}$ & 904.2 & 825 & 756.9 & 738.5 & 680.8 & 1004.65 \\
$B O S_{c}^{r e f}$ & 369.3 & 275 & 309.1 & 237.5 & 239.2 & 410.35 \\
\hline \hline
\end{tabular}

Table 6: Investment costs data (euros/kW of installed power).

\begin{tabular}{lcccccc}
\hline \hline Country & France & Spain & Italy & Germany & Portugal & Denmark \\
\hline $\begin{array}{l}\text { Average realized } \\
\begin{array}{l}\text { capacity factors } \\
\text { between 2003 and 2007 }\end{array}\end{array}$ & $22.3 \%$ & $24.8 \%$ & $19.1 \%$ & $18.3 \%$ & $22.7 \%$ & $22.8 \%$ \\
\hline \hline
\end{tabular}

Table 7: National capacity factors for a typical wind power plant.

\begin{tabular}{ccccccccc}
\hline \hline & RWE & E.ON & EDF & GDF & ENEL & Endesa & Iberdrola & EDP \\
\hline Beta & 0.63 & 0.65 & 0.94 & 0.83 & 0.63 & 0.79 & 0.85 & 0.84 \\
$\begin{array}{c}\text { Estimation } \\
\text { period }\end{array}$ & $2000-10$ & $2000-10$ & $2006-10$ & $2008-10$ & $2000-10$ & $2000-10$ & $2000-10$ & $2000-10$ \\
Data points & 156 & 156 & 84 & 52 & 156 & 156 & 156 & 156 \\
\hline \hline
\end{tabular}

Table 8: Estimates of electricity companies' betas (all parameters are significant at the $1 \%$ level). 

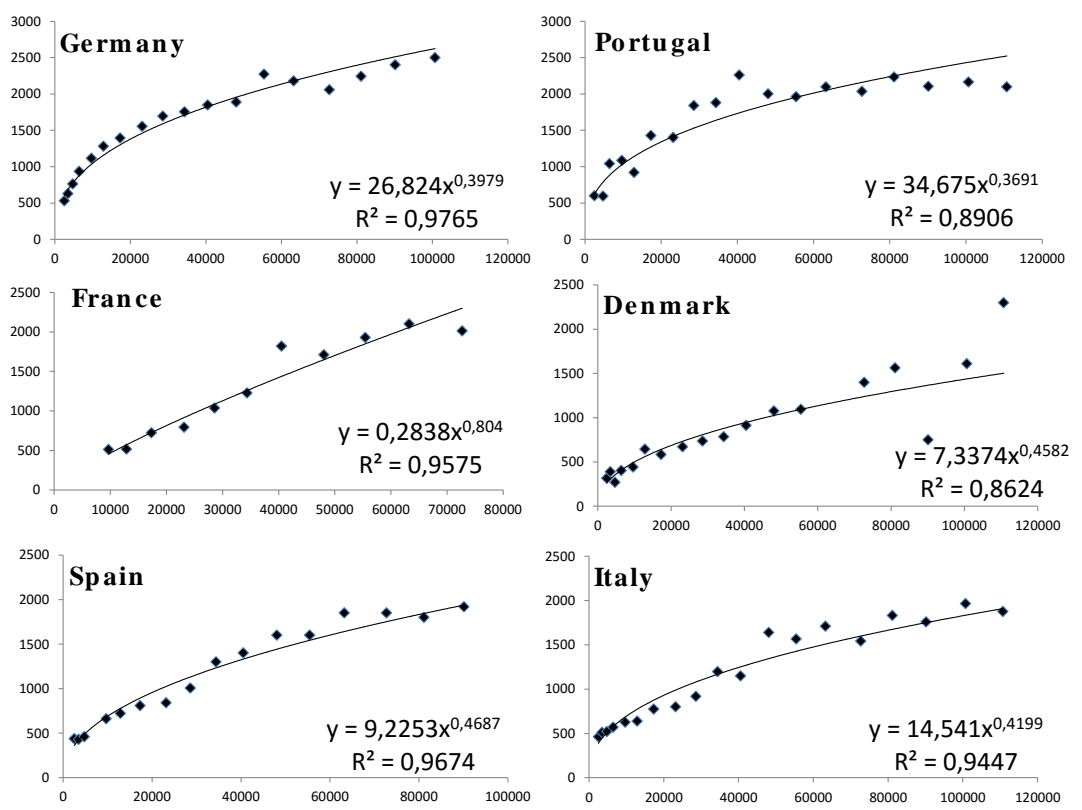

Figure 7: Estimations of the relation between average turbines rated power and lagged European cumulative capacity, per country.

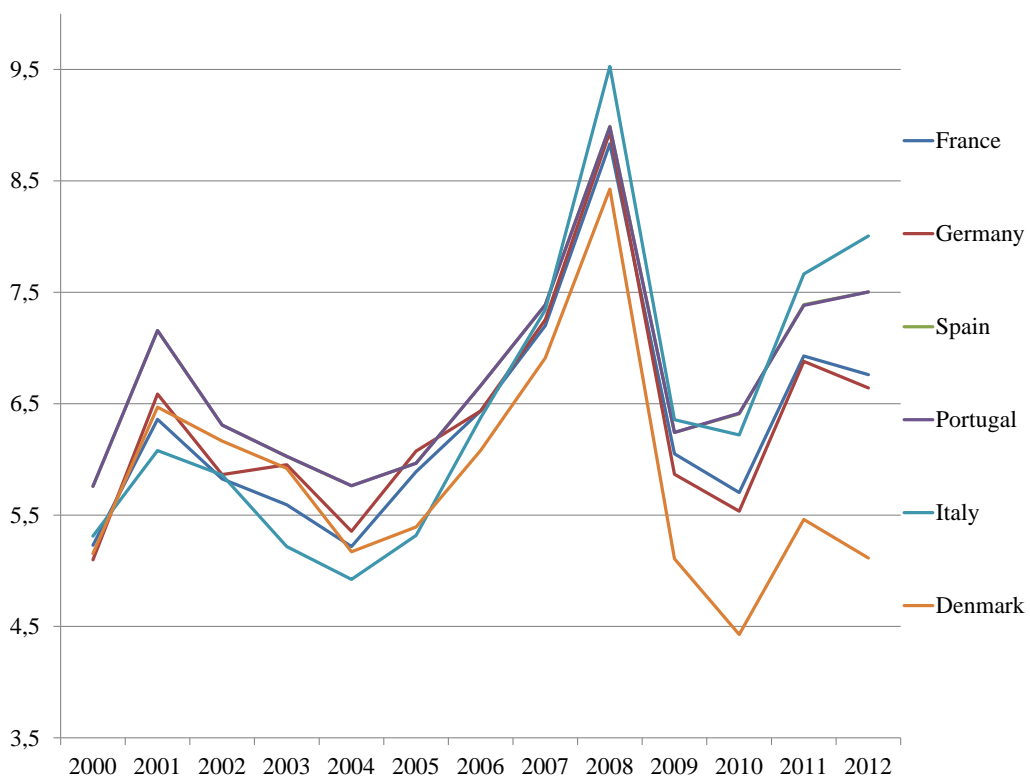

Figure 8: Estimated CAPM-based discount rates per country, expressed in \%. 


\begin{tabular}{c|cccc}
\hline \hline & Steel & Iron/Cast Iron & Copper & Aluminium \\
\hline Vestas V82 & 70 & 13 & 1 & 1 \\
Gamesa G8X & 74 & 15 & 2 & 0 \\
Vestas V80 & 81 & 8 & 1 & 1 \\
Vestas V112 & 66 & 18 & 1 & 1 \\
Weights & 72.75 & 13.5 & 1.25 & 0.75 \\
\hline \hline
\end{tabular}

Table 9: Metals weights, from [7] (in \% of turbines' masses).

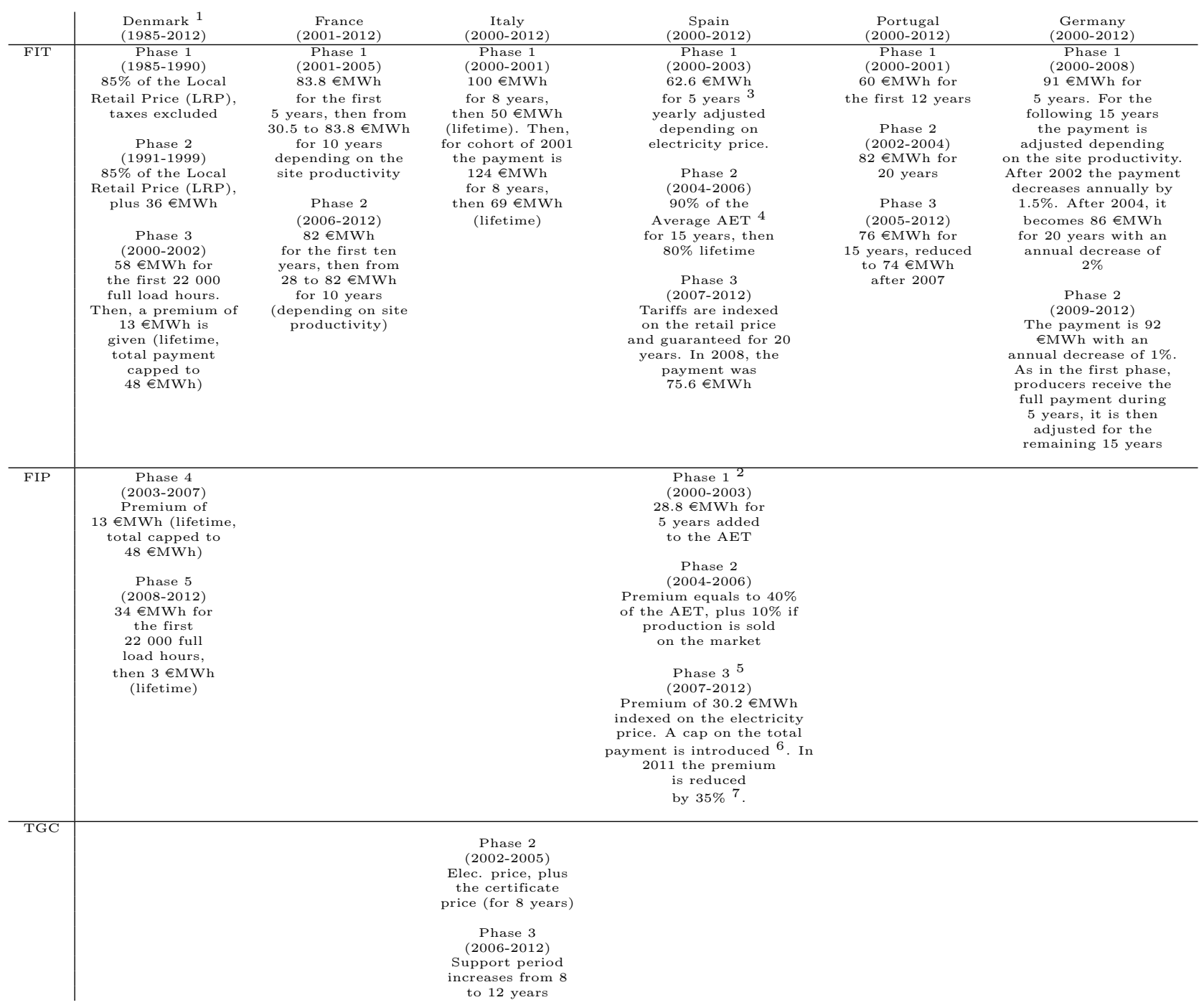

Table 10: Summary of the history of demand-pull support policies to onshore wind power in six European countries. 


\begin{tabular}{|c|c|c|c|c|c|c|c|}
\hline \multirow{3}{*}{$\sigma$} & & $\mathrm{DE}$ & FR & IT & $\mathrm{PT}$ & SP & DK \\
\hline & $-1 \%$ & 0,0032 & 0,0585 & 0,1512 & 0,0934 & 0,003 & 0,0131 \\
\hline & $+1 \%$ & $-0,0022$ & $-0,0706$ & $-0,2582$ & $-0,112$ & $-0,0038$ & $-0,0075$ \\
\hline \multirow[t]{2}{*}{$\mu_{0}$} & $-1 \%$ & $-0,008$ & $-0,1405$ & $-0,3165$ & $-0,1572$ & $-0,0126$ & $-0,0178$ \\
\hline & $+1 \%$ & 0,00936 & 0,11 & 0,1907 & 0,12 & 0,0123 & 0,0306 \\
\hline \multirow[t]{2}{*}{$\beta$} & $-1 \%$ & 0,0009 & 0,0062 & $-0,0182$ & 0,0018 & 0,0007 & $-0,0034$ \\
\hline & $+1 \%$ & $-0,0003$ & $-0,0088$ & 0,0065 & $-0,0032$ & $-0,0011$ & $-0,001$ \\
\hline \multirow[t]{2}{*}{$\theta$} & $-1 \%$ & 0,0057 & 0,0558 & 0,0538 & 0,048 & 0,0081 & 0,0195 \\
\hline & $+1 \%$ & $-0,0035$ & $-0,0526$ & $-0,0298$ & $-0,0371$ & $-0,0057$ & $-0,0263$ \\
\hline \multirow[t]{2}{*}{$d_{c}$} & $-1 \%$ & 0 & $1,0728 * 10^{-16}$ & 0 & 0 & $1,1224 * 10^{-16}$ & 0 \\
\hline & $+1 \%$ & 0 & $-7,1003 * 10^{-17}$ & 0 & 0 & $8,23515 * 10^{-17}$ & 0 \\
\hline \multirow[t]{2}{*}{$b_{c}$} & $-1 \%$ & $-0,0007$ & $-0,0223$ & $-0,0298$ & $-0,0139$ & $-0,0027$ & $-0,0238$ \\
\hline & $+1 \%$ & 0,0012 & 0,015 & $-0,013$ & 0,0091 & 0,0015 & 0,013 \\
\hline \multirow[t]{2}{*}{$Q_{c}^{r e f}$} & $-1 \%$ & $-0,0002$ & $-0,0023$ & $-0,0155$ & 0,0033 & $-0,0005$ & 0,0002 \\
\hline & $+1 \%$ & 0,0007 & $-0,0002$ & 0,0038 & $-0,0046$ & 0,0002 & $-0,0046$ \\
\hline \multirow[t]{2}{*}{$T C_{c}^{r e f}$} & $-1 \%$ & 0,0005 & 0,001 & $-0,0025$ & $-0,0053$ & 0,0002 & $-0,0049$ \\
\hline & $+1 \%$ & $-3,4991 * 10^{-5}$ & $-0,0041$ & $-0,0182$ & 0,0032 & $-0,0007$ & 0,0002 \\
\hline \multirow[t]{2}{*}{$O \& M$} & $-1 \%$ & $-0,0049$ & $-0,057$ & $-0,0235$ & $-0,0308$ & $-0,0079$ & $-0,0125$ \\
\hline & $+1 \%$ & 0,0053 & 0,0457 & $-0,0066$ & 0,0254 & 0,0066 & 0,0028 \\
\hline \multirow[t]{2}{*}{$B O S_{c}^{r e f}$} & $-1 \%$ & 0,0005 & $-0,0015$ & $-0,0025$ & 0,0001 & $-3,129 * 10^{-5}$ & $9,1186 * 10^{-5}$ \\
\hline & $+1 \%$ & $-0,0001$ & $-0,0016$ & $-0,0182$ & $-0,0022$ & $-0,0005$ & $-0,0045$ \\
\hline
\end{tabular}

Table 11: Results of the sensitivity analysis. 